\title{
Climatic Properties of Tropical Precipitating Convection under Varying Environmental Conditions
}

\author{
Anthony D. Del Genio \\ NASA Goddard Institute for Space Studies, New York, New York \\ WILliAM KOVARI \\ Institute for Space Studies, Columbia University, New York, New York
}

(Manuscript received 16 November 2001, in final form 18 March 2002)

\begin{abstract}
A clustering algorithm is used to define the radiative, hydrological, and microphysical properties of precipitating convective events in the equatorial region observed by the Tropical Rainfall Measuring Mission (TRMM) satellite. Storms are separated by surface type, size, and updraft strength, the latter defined by the presence or absence of lightning. SST data and global reanalysis products are used to explore sensitivity to changes in environmental conditions. Small storms are much more numerous than mesoscale convective systems, and account for fairly little of the total rainfall but contribute significantly to reflection of sunlight. Lightning storms rain more heavily, have greater cloud area, extend to higher altitude, and have higher albedos than storms without lightning. Lightning is favored by a steep lower-troposphere lapse rate and moist midlevel humidity. Storms occur more often at SST $\geq 28^{\circ} \mathrm{C}$ and with strong upward 500 -mb mean vertical velocity. In general, storms over warmer ocean waters rain more heavily, are larger, and have higher cloud tops, but they do not have noticeably higher albedos than storms over cooler ocean waters. Mesoscale convective system properties are more sensitive to SST. Rain rates and cloud-top heights increase statistically significantly with mean upward motion. Rain rates increase with albedo and cloud-top height over ocean, but over land there are also storms with cloud-top temperatures $>-35^{\circ} \mathrm{C}$ whose rain rates decrease with increasing albedo. Both the fraction of available moisture that rains out and the fraction that detrains as ice increase with SST, the former faster than the latter. TRMM ice water paths derived from cloud-resolving models but constrained by observed microwave radiances are only weakly correlated with observed albedo. The results are inconsistent with the "adaptive iris" hypothesis and suggest feedbacks due primarily to increasing convective cloud cover with warming, but more weakly than predicted by the "thermostat" hypothesis.
\end{abstract}

\section{Introduction}

The sensitivity of the earth's climate to external perturbations is the largest uncertainty in projections of twenty-first-century climate change (Wigley and Raper 2001). The Intergovernmental Panel on Climate Change Third Assessment Report (Houghton et al. 2001) estimates the uncertainty range of global climate sensitivity due to a doubling of $\mathrm{CO}_{2}$ concentration as $1.5^{\circ}-4.5^{\circ} \mathrm{C}$, unchanged over $20 \mathrm{yr}$ of research. The lack of observable constraints on cloud feedback is the major reason why the range of estimates has not narrowed. Deep convective clouds and the areally extensive anvils sometimes associated with them are the dominant clouds in the Tropics, accounting for the visible appearance of the intertropical convergence zone in satellite imagery. Since convection is expected to respond strongly to

Corresponding author address: Anthony D. Del Genio, NASA GISS, 2880 Broadway, New York, NY 10025.

E-mail: adelgenio@giss.nasa.gov forced anthropogenic climate change, deep convective systems should play a large role in determining the global cloud feedback.

The response of convective and anvil clouds to climate perturbations depends on poorly understood details of their water budgets (Gamache and Houze 1983). Thermodynamic properties of boundary layer air determine the potential condensate available to form uppertroposphere cloud. Entrainment of environmental air and precipitation fallout deplete condensate in the updraft; that which survives the lifting detrains as parcels lose buoyancy and forms the anvil cloud. Two completely divergent views of the response of convective cloud systems to changes in surface temperature have been proposed. The "thermostat" hypothesis (Ramanthan and Collins 1991) argues that enhanced moisture in boundary layer air over warm oceans leads to thicker, more extensive anvil clouds. The shortwave cooling of these clouds exceeds their longwave warming, implying a negative cloud feedback, that is, the net radiative effect of the cloud increase is to counteract the warming that 
produces it. The "adaptive iris" hypothesis (Lindzen et al. 2001) claims that increased precipitation efficiency of convection over warmer oceans leads to thinner, less extensive anvils. This paper assumes [mistakenly, according to Lin et al. (2001)] that the longwave warming of these clouds dominates their shortwave cooling, so an anvil cloud decrease primarily allows more heat to escape to space and produces a negative feedback. Both claim to be supported by satellite observations, but most likely, each one actually reveals a correlation with largescale vertical velocity rather than temperature (cf. Fu et al. 1992; Hartmann and Michelsen 2002).

Uncertainty in the details of the water budget translates into uncertainty in climate sensitivity. Del Genio et al. (1996) show that cloud feedback in the Goddard Institute for Space Studies (GISS) GCM in response to idealized SST perturbations can be of either sign depending on details of the SST anomaly. A spatially uniform SST change causes a negative cloud feedback (i.e., a decrease in net radiation). When the SST anomaly is instead assumed to weaken the SST gradient across the tropical Pacific as the climate warms, the cloud feedback is positive (increased net radiation) instead. This difference in sensitivity occurs because the warm climate Walker cell is stronger in the first scenario than in the second, and thus moisture convergence increases more with warming in the first scenario, leading to more and thicker anvil clouds. Yao and Del Genio (1999) show that the doubled $\mathrm{CO}_{2}$ climate sensitivity of a similar model increases by $0.6^{\circ} \mathrm{C}$ when cumulus condensate detrainment is not permitted (i.e., $100 \%$ precipitation efficiency) because tropical upper-troposphere ice increases very little in the latter experiment.

The GISS GCM uses a mass flux cumulus parameterization that does not allow for changes in updraft strength to interact with the microphysics. Recently, parameterizations that predict or diagnose cumulus updraft speeds have been proposed (cf. Donner et al. 2001; Gregory 2001), but none has been applied to a climate change scenario nor have the consequences of their predicted updrafts been validated against observations. We expect slightly stronger updrafts in a warmer climate, because of increased parcel buoyancy associated with the increased contribution of water vapor to virtual temperature (Ye et al. 1998). However, changes in the partitioning of the water budget between the precipitation sink and detrainment source are difficult to anticipate, and even the inference of stronger updrafts itself does not account for unknown changes in midtroposphere humidity and trade inversion strength.

Recent observations have shed light on the relationship among convective intensity, convective cloud properties, and the convective environment. Ye (1999) shows that large convective clusters form in environments preconditioned with higher midtroposphere relative humidity than do smaller clusters, consistent with cloudresolving model results (Lucas et al. 2000). Ye also finds that the optically thickest clusters are relatively small and tend to form in the presence of front-to-back uppertroposphere wind shear. Boccippio et al. (2000) find that lightning flash rates (an assumed proxy for updraft strength near the freezing level) negatively correlate with the mean gross moist stability of the free troposphere. Nesbitt et al. (2000) demonstrate that convective systems with $85-\mathrm{GHz}$ ice scattering signatures (an indicator of large ice particles) have more frequent lightning than do systems without observable ice scattering.

For cloud feedback, the important aspects of convective systems are their effects on shortwave and longwave radiation. The Nesbitt et al. results might imply that stronger convective storms reflect more sunlight. However, the $85-\mathrm{GHz}$ signal is sensitive only to large ice particles, and there is uncertainty about the relative contribution of large versus small ice particles to anvil albedo. Heymsfield and McFarquhar (1996) argue, based on aircraft data, that large $(>100 \mu \mathrm{m})$ ice crystals control anvil albedos. Jensen and Del Genio (2002, manuscript submitted to J. Appl. Meteor.) use radar reflectivity profiles and a radiative transfer model to show that observed albedos of convective systems are better matched by varying the ice content of small particles than by reasonable changes in the properties of large ice or precipitating liquid droplets. Furthermore, lightning storms are a small fraction of the total, and although intense storms contribute most of the rainfall (Mohr et al. 1999; Nesbitt et al. 2000) they do not dominate the radiative impact of tropical convective systems (Machado et al. 1998; Ye 1999). It is therefore necessary to understand the factors controlling the properties of the more frequent smaller, weaker storms as well.

We address these issues using data from three instruments on the NASA Tropical Rainfall Measuring Mission (TRMM) satellite: The TRMM Microwave Imager (TMI), which provides surface rainfall rates and hydrometeor profiles; the Lightning Imaging Sensor (LIS), which we use to separate strong from weak convection; and the Clouds and the Earth's Radiant Energy System (CERES), which provides shortwave albedos and outgoing longwave radiation. Section 2 describes the datasets, analysis methods, and basic statistics for tropical convective systems. Section 3 examines differences in the properties of lightning and nonlightning storms. Section 4 explores how storm properties vary with largescale environmental factors. We discuss implications for cloud feedback and cumulus parameterization development in section 5.

\section{Data and methods}

The TRMM satellite was launched into a $350-\mathrm{km}$ altitude, $35^{\circ}$ inclination orbit in late 1997 , with standard data products issued beginning in February 1998. The satellite completes 16 orbits per day and acquires data in either cross-track swaths of varying width or in twodimensional domains. We use data from three TRMM 
TABLE 1. Characteristics of TRMM instrument datasets used in this paper.

\begin{tabular}{lccc}
\hline \hline Instrument & Spectral coverage & Nadir resolution $(\mathrm{km})$ & Swath/domain size \\
\hline TMI & $10.65,19.35,21.3,37.0,85.5 \mathrm{GHz}$ & $4 \mathrm{~km} \times 7 \mathrm{~km}, 7 \mathrm{~km}$ separation between scans & $759-\mathrm{km}$ swath \\
LIS & $0.7774 \mu \mathrm{m}$ & $4 \mathrm{~km}$ & $600 \times 600 \mathrm{~km}$ \\
CERES & $0.2-5,0.2-100,8-12 \mu \mathrm{m}$ & $10 \mathrm{~km}$ & $\sim 2000-\mathrm{km}$ radius circle \\
\hline
\end{tabular}

instruments (details given in Table 1) and supplementary datasets as follows.

The TMI (Kummerow et al. 1998) Version 5 2A-12 rainfall algorithm (Kummerow et al. 2001) uses a Bayesian approach to predict the probability of a given rain rate by searching a database of hydrometeor profiles and microwave brightness temperatures computed from simulations from two cloud-resolving models (CRMs). Gaussian weights for each profile are determined by the root-mean-square differences between observed and computed sets of brightness temperatures. Mean 2A-12 rainfall rates are $20 \%-25 \%$ higher than those from the TRMM precipitation radar (PR), and PR more often produces weak rain rates. Inspection of individual TMI and PR images suggests that TMI tends to predict less rainfall than PR for the smallest storms. The LIS (Christian 1999) is a staring optical imager that detects 90\% of in-cloud and cloud-to-ground lightning. In this paper we utilize the occurrence or absence of lightning as an index for strong versus weak midtroposphere updrafts in storms. The CERES is a follow-on to the Earth Radiation Budget Experiment (ERBE; Wielicki et al. 1996). We use the CERES ES-8 (ERBE-like instantaneous top-of-atmosphere) products, which use the ERBE angular distribution models to convert radiances to fluxes, and to calculate outgoing longwave (OLR) and reflected shortwave (SW) fluxes and broadband storm cloud albedos.

The National Centers for Environmental PredictionNational Center for Atmospheric Research (NCEPNCAR) reanalysis (Kalnay et al. 1996) is used to examine the relationship of storms to several environmental parameters thought to influence convection. Reanalysis parameters are defined every $12 \mathrm{~h}$ on a $2.5^{\circ} \times$ $2.5^{\circ}$ grid; we use the nearest value within $\pm 6 \mathrm{~h}$ of the time of the observed storm for the grid box that contains the storm center. We use the analyzed large-scale monthly mean pressure vertical velocity $\langle\omega\rangle$ at $500 \mathrm{mb}$. This is a B-level value in the reanalysis hierarchy, meaning that it is constrained by the observations but also influenced by the characteristics of the underlying model. (Tests using the instantaneous $\omega$ product suggest that it has little information content in the Tropics.) We repeated our analyses with three other instantaneous reanalysis products that should be related to large-scale vertical velocity: $500-$ and $850-\mathrm{mb}$ relative humidity (also a B-level parameter), and a lapse rate index defined as the difference between 850 - and $500-\mathrm{mb}$ temperature (an A-level parameter, considered well defined by the analysis system). We also analyze storm properties as a function of SST obtained from the Hadley Centre Ice and SST (HadISST) climatology (Rayner et al. 2002). Wind shear can affect storms as well but has been excluded from this analysis because TRMM does not provide the storm propagation direction required to characterize the role of shear.

Satellite pixels with nonzero rain rate at the surface, and in addition with cloud water above the 5-km level, are assumed to be associated with deep convective systems. Some of these, though, with tops close to the freezing level (OLR $\sim 300 \mathrm{~W} \mathrm{~m}^{-2}$ or greater) may actually be cumulus congestus (Johnson et al. 1999). Others may be stratiform anvils remaining after a prior convective event. We use a clustering algorithm (Machado et al. 1998) to define a single "storm" as all contiguous raining TMI pixels with cloud above $5 \mathrm{~km}$. Individual cells within a mesoscale cluster separated by areas with cloud but no rain are therefore counted as separate storms. However, visual inspection of TMI images indicates that the vast majority of storms defined in this way are isolated convective events. Only storms containing at least four contiguous raining TMI pixels, an area roughly equivalent to the CERES pixel resolution, are included to minimize biases in radiative properties due to partly cloudy CERES pixels. However, for the smaller storms, the different CERES and TMI resolutions produce varying degrees of overlap. The finite width of the TMI swath means that some larger storms do not completely fall within the TMI field of view. Nesbitt et al. (2000), who analyze storms in TRMM PR data, estimate that truncation at the edge of the narrow PR swath $(215 \mathrm{~km})$ affects $17 \%$ of their storms, 54\% of mesoscale storms with $85-\mathrm{GHz}$ ice scattering signatures, and $82 \%$ of the more intense mesoscale storms. This bias should be significantly reduced in our analysis, since only $5 \%$ of our storms have diameters $>10 \%$ of the 759-km TMI swath width (see Fig. 1).

Cumulus mass flux, a fundamental quantity for parameterization closure assumptions, is the product of updraft area and strength. We therefore classify storms in two ways.

1) We define a storm equivalent radius $R$ as the radius of a circle whose area equals the contiguous area of deep precipitating TMI pixels. Storms with $R>25$ $\mathrm{km}\left(\sim 2000 \mathrm{~km}^{2}\right)$ are classified as mesoscale convective systems (MCSs). These storms bear some resemblance to those defined as MCSs by Mohr and Zipser (1996) on the basis of the 85-GHz ice scattering signature but are not identical, since the precipitating area of a storm may be larger than the area containing large ice particles aloft. (Note that since 
TABLE 2. Number of storms segregated by surface type, size, and strength. The sum of land and ocean storms does not always equal "all" storms because of a small number of additional "coastal" storms that contain TMI pixels with both land and ocean underlying surface types.

\begin{tabular}{lrrr}
\hline \hline & Ocean & Land & \multicolumn{1}{c}{ All } \\
\hline All storms & 6765 & 1773 & 8786 \\
Lightning & 38 & 119 & 171 \\
Nonlightning & 6727 & 1654 & 8615 \\
MCSs & 764 & 158 & 925 \\
Lightning & 28 & 50 & 78 \\
Nonlightning & 736 & 108 & 847 \\
\hline
\end{tabular}

there is a 7-km gap between adjacent TMI scans at $85.5 \mathrm{GHz}$, the storm equivalent radius is only loosely related to actual storm size, which will vary depending on the storm's detailed shape and orientation relative to the scan direction.)

2) We define "strong" storms as those with at least one LIS lightning detection within $\pm 0.0625^{\circ}$ of a TMI storm pixel and "weak" storms as all others with no lightning detection. The qualitative association of lightning with strong convection is supported by numerous studies (cf. Zipser and Lutz 1994), which suggest that mean updraft strengths $>\sim 6-7 \mathrm{~m} \mathrm{~s}^{-1}$ are required to lift significant amounts of supercooled liquid water into the ice phase region and initiate the microphysical charge exchange processes that lead to lightning. However, since TRMM only provides an instantaneous storm snapshot, the absence of lightning at the time of observation does not guarantee that the storm never produced lightning during its life cycle. Thus, our weak storms may include several strong examples. Even with this limitation, there are obvious differences between storms with and without observed lightning. An extremely small percentage of all storms produce lightning, so our weak storm statistics should not be significantly biased.

The techniques described above were applied to all 65 orbits of TRMM data for the period 1-5 February 1998. This is not a sufficiently long time period to observe the diurnal cycle in any individual region, since the non-sun-synchronous orbit requires about 47 days to fully sample the diurnal cycle in any location. However, it does provide a representative diurnal and synoptic timescale sample of statistics compiled over all tropical land and ocean areas, which are the focus of this paper. Basic features in the figures we present are evident in samples as small as 1-2 days and consistent with longer regional surveys. We restrict discussion to equatorial region $\left(15^{\circ} \mathrm{N}-15^{\circ} \mathrm{S}\right)$ storms, whose characteristics and relationship to environmental conditions are somewhat different from TRMM-observed storms at higher latitudes that are sometimes associated with the equatorward extensions of midlatitude baroclinic systems.
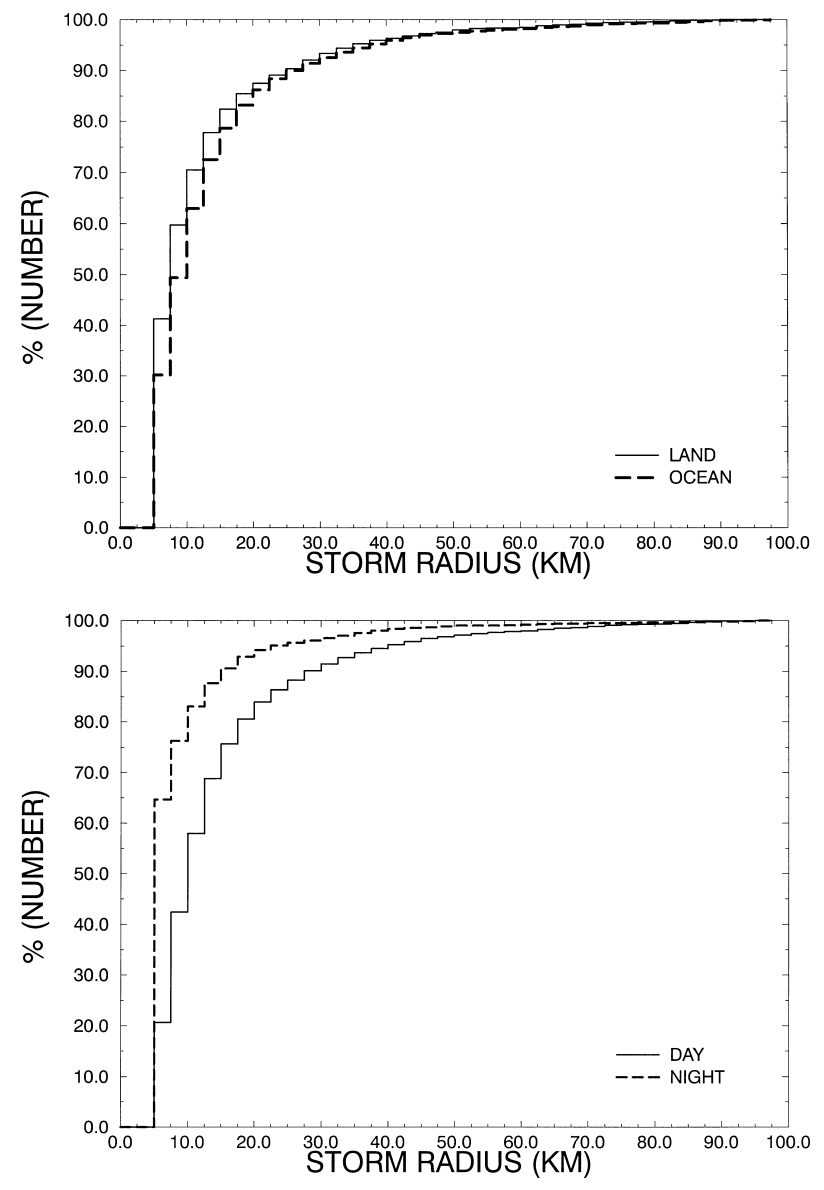

FIG. 1. Cumulative distribution functions of storm radius for (upper) land and ocean storms, and (lower) day and night storms.

Table 2 gives the statistics of all equatorial region storms, sorted by surface type, size, and strength. Our technique detects 8786 storms over the 5-day period. Of these, $77 \%$ are ocean storms, comparable to the oceanic percentage of the surface area of the $15^{\circ} \mathrm{N}-15^{\circ} \mathrm{S}$ latitude band. MCSs as we define them are the largest $10 \%$ of the size distribution. Per unit area, MCSs are slightly more common over ocean $(83 \%$ of all MCSs occur over ocean). Only $2 \%$ of the storms have detectable lightning at the time of observation, but $8 \%$ of MCSs are lightning storms. Lightning storms are far more common over land (78\% of the total) than ocean. Most ocean lightning storms are MCSs (74\%), while slightly less than half of all land lightning storms (42\%) are MCSs. Deep precipitating storms cover $\sim 3 \%$ of the $15^{\circ} \mathrm{N}-15^{\circ} \mathrm{S}$ area on average, consistent with previous estimates of deep convective cloud cover (Fu et al 1990).

Figure 1 shows cumulative distribution functions of storm frequency as a function of size for land versus ocean storms (upper) and day versus night storms (lower). As has been noted by previous workers, the vast majority of tropical storms are small; our definition of MCSs includes only $10 \%-15 \%$ of all TRMM-resolved 

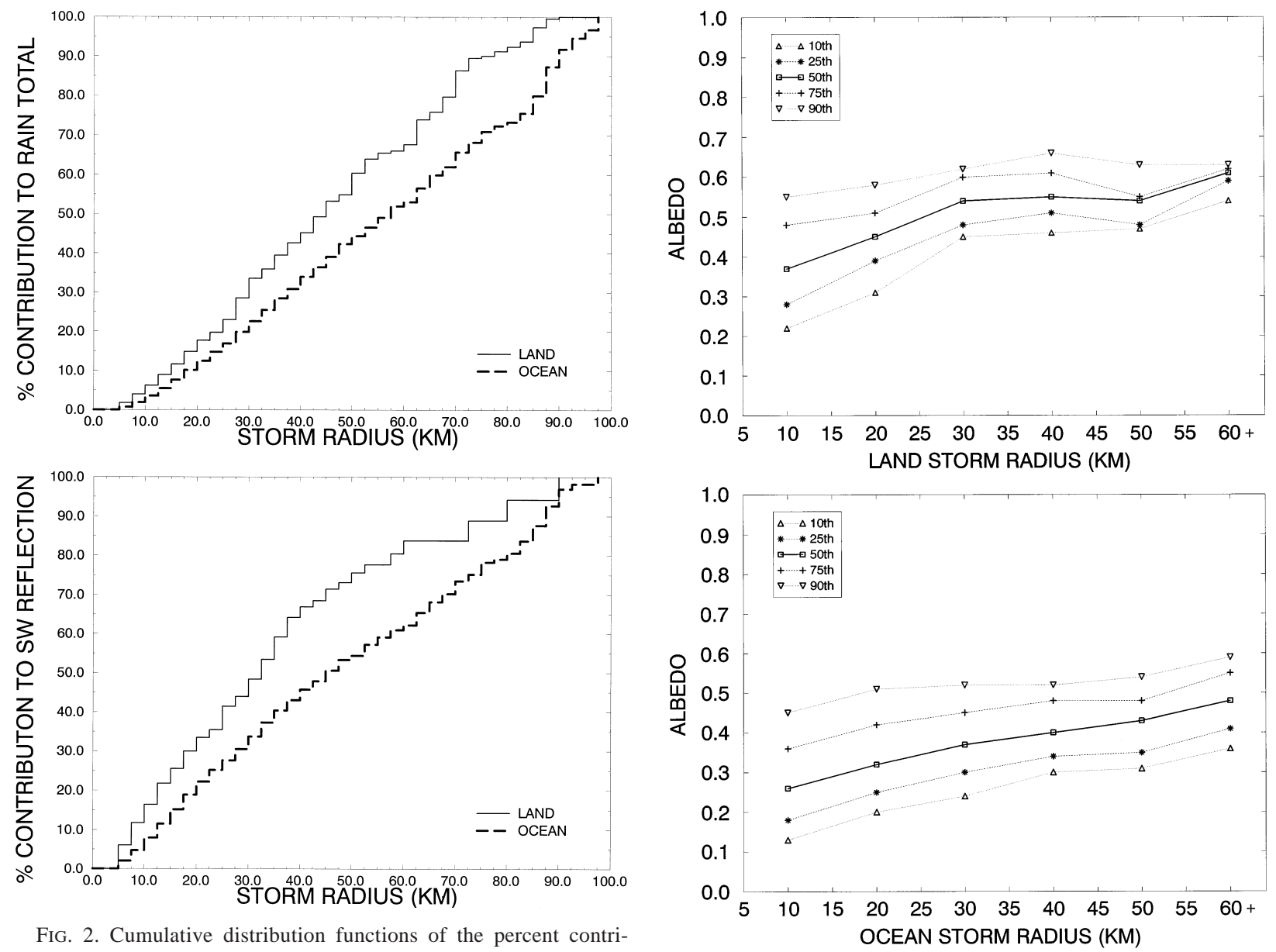

FIG. 2. Cumulative distribution functions of the percent contributions to (upper) rain total and (lower) shortwave reflection by land and ocean storms.

storms over both land and ocean. The median equivalent radius of ocean storms is a few kilometers larger than that for land storms, but land and ocean size distributions are generally quite similar. (The results are similar when storms down to one raining TMI pixel are included, but we have no information on storms smaller than the $\sim 5-\mathrm{km}$ TMI resolution.) Daytime storms are considerably larger than nighttime storms, over both land and ocean, a somewhat surprising result given the different diurnal cycles of land and ocean convection. In fact, the majority of night storms are at the smallest sizes we can resolve. The largest $10 \%$ of storms have radii $>30 \mathrm{~km}$ in daytime and $>17.5 \mathrm{~km}$ at night.

Of more interest is the contribution of storms of different sizes to the water and energy budgets. Figure 2 shows land and ocean cumulative frequency distributions of the contributions of storms of different sizes to total surface rain volume (upper) and shortwave reflection (lower). The rain distributions are nearly linear, confirming the well-known importance of large systems to the total rain budget. MCSs, which account for only $10 \%-15 \%$ of all storms, provide $85 \%$ of the total rain over ocean and $77 \%$ over land; this is consistent with

FIG. 3. Albedo vs storm radius (km) for (upper) land and (lower) ocean storms. Plotted are the median and the 10th, 25th, 75th, and 90th percentile values for storms aggregated in $10-\mathrm{km}$-wide radius bins. The final bin includes all storms with radius $>55 \mathrm{~km}$.

shipboard radar estimates in the tropical west Pacific (Rickenbach and Rutledge 1998). Thus, it is not surprising that most research on tropical convection has focused on organized mesoscale systems, which contribute most to the latent heating. The radiative impact of large storms is not quite as dominant, with $75 \%$ of all shortwave reflection coming from MCSs over ocean and only $65 \%$ over land. (The gap between TMI swaths implies that some smaller storms might have clear regions within the CERES footprint, causing their albedos to be underestimated.) When nonprecipitating cloudy areas of storms are included, the contribution of small storms to shortwave reflection in fact becomes comparable to that of large storms (Ye 1999). The collective radiative contributions of the much more numerous small storms might therefore be important in a climate change.

Further information on the radiative properties of convective storms is obtained by examining the relationship between albedo and size (Fig. 3). Median storm albedo increases with increasing size but varies little at the 
largest sizes. The more numerous smaller storms have a broader distribution of albedos than the more infrequent MCSs. Surprisingly, the brightest storms (not shown) are small, isolated cells or small clusters of cells, usually over land. Ye [(1999); see also Del Genio (2001), Fig. 2] shows that maximum visible optical thicknesses during Tropical Ocean Global Atmosphere Comprehensive Ocean-Atmosphere Response Experiment (TOGA COARE) are also associated with the smallest storms, so these appear to be real rather than spurious features. Aside from these anomalous storms, land storms tend to be brighter on average than ocean storms at any size.

Since the TMI 2A-12 algorithm is based on CRM simulations, the product includes derived vertical profiles of hydrometeor mass density in four classes (precipitating liquid and ice and cloud liquid and ice). Condensate distributions are quite variable from one CRM to another ( $\mathrm{Xu}$ et al. 2002), since they use different microphysics parameterizations or parameter settings. The 2A-12 hydrometeor profiles are constrained by observed microwave radiances. Emission by both large and small liquid droplets affects brightness temperature at the lower TMI frequencies, while scattering by large ice particles depresses the $85-\mathrm{GHz}$ brightness temperature (Adler et al. 1991; Smith et al. 1992). On the other hand, small ice particles have no microwave signature, so the 2A-12 cloud ice profiles are completely a product of the underlying CRM microphysics assumptions. Shortwave radiation, however, is quite sensitive to small ice particles, and moderately sensitive to large ice particles (Jensen and Del Genio 2002, manuscript submitted to J. Appl. Meteor.), so the CERES data provide an independent test of the information content in the $2 \mathrm{~A}$ 12 hydrometeor profiles.

Figure 4 shows the composite vertical profiles of all four hydrometeor classes over ocean and land, separated by the presence or absence of lightning. Rainwater content increases slightly with height up to $2 \mathrm{~km}$ altitude for all storm types and decreases to zero at 8-10 km. Cloud liquid water peaks at higher altitudes $(4-5 \mathrm{~km})$ and persists to higher altitude than does rainwater. Land storms have more rainwater and cloud liquid water than ocean storms, and lightning storms have more than nonlightning storms. Precipitating ice (graupel, snow) peaks at $6 \mathrm{~km}$ altitude, $\sim 1 \mathrm{~km}$ above the freezing level, for all storm types. Lightning storms have more large particle ice over land than ocean, but the reverse is true for nonlightning storms. Cloud ice mass peaks near the storm top (14 km altitude) and is insignificant for land storms, but these results must be viewed with caution since cloud ice has minimal impact on microwave radiances and is sensitive to parameter setting assumptions in CRMs. Despite much evidence that lightning requires large amounts of supercooled water above the freezing level (cf. Zipser and Lutz 1994; Petersen et al. 1996), the CRM simulations show little difference in the ver- tical profiles of liquid water above the freezing level for lightning and nonlightning storms.

\section{Effect of storm strength on storm properties}

Since lightning implies strong updrafts near the freezing level, a comparison of storms with and without lightning can provide indirect inferences about the link between cumulus dynamics and microphysics. Mean properties of storms with and without lightning over ocean and land, as well as information about the large-scale environment in which each storm type exists, are presented in Table 3. Figure 5 shows normalized histograms of surface rain rate and storm size, while Fig. 6 shows normalized histograms of albedo and OLR, for each storm type.

Over both ocean and land, lightning storms rain much more heavily than nonlightning storms and are several times as large. For nonlightning storms, which are most of the total, the histograms of both rain rate and size are highly skewed. Lightning storm rain rates and sizes, on the other hand, are well separated from their nonlightning counterparts but otherwise almost uniformly distributed. Albedos of lightning storms over ocean are almost twice as large as for nonlightning storms and their distributions are well separated. Land lightning storms, on the other hand, are only slightly brighter than their nonlightning counterparts, and the distributions overlap almost completely. Over both land and ocean, lightning storms have lower OLR values consistent with $2-3 \mathrm{~km}$ higher cloud tops than nonlightning storms. The mean heights of lightning storms are virtually identical over land and ocean, and only small differences exist for nonlightning storms over land and ocean. The distributions of the latter, however, are quite different: over land, relatively few storms have OLR $>275 \mathrm{~W} \mathrm{~m}^{-2}$, while over ocean, the distribution is more highly skewed with the mode value $275-300 \mathrm{~W} \mathrm{~m}^{-2}$. These correspond to cloud-top heights within 1-2 km above the freezing level, the signature of cumulus congestus that lose buoyancy in a dry or weakly stable layer near the freezing level before glaciating (Johnson et al. 1999). Large particles dominate the cloud mass for all storm categories. Ice accounts for more of the mass than liquid for ocean storms, but ice and liquid are comparable for land storms. Cloud ice is negligible in the TMI land hydrometeor profiles, but it accounts for significant mass in ocean lightning cases, which may help explain the high albedos of ocean lightning storms.

For this information to be useful as a parameterization constraint, we must understand the environmental conditions that favor or suppress lightning, since lightning occurrence is not predicted directly in GCMs. Lightning requires strong cumulus updrafts and is thus favored by a moist boundary layer and steep lapse rates above. Other predictors include upward large-scale vertical velocity, which implies adiabatic cooling and steepening lapse rate, and midlevel relative humidity, since the 
OCEAN LIGHTNING

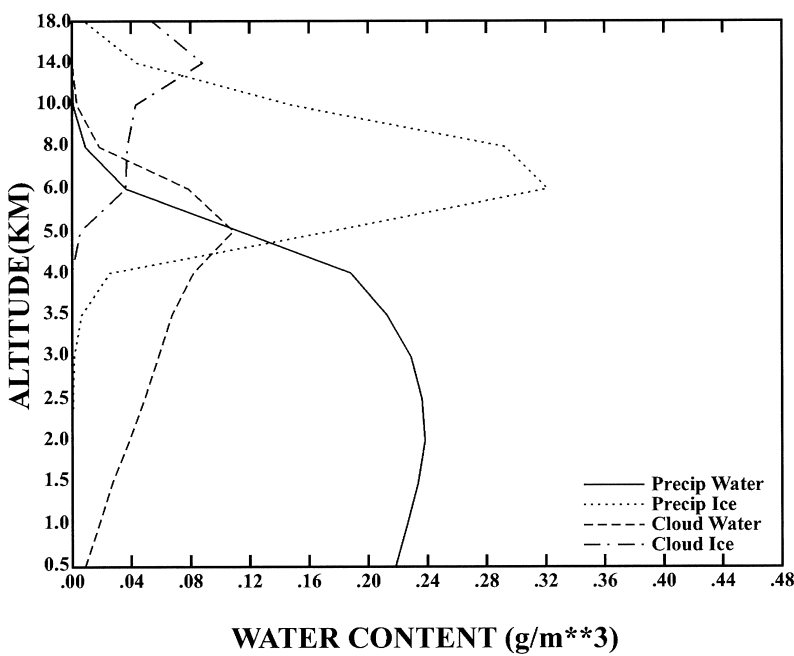

LAND LIGHTNING

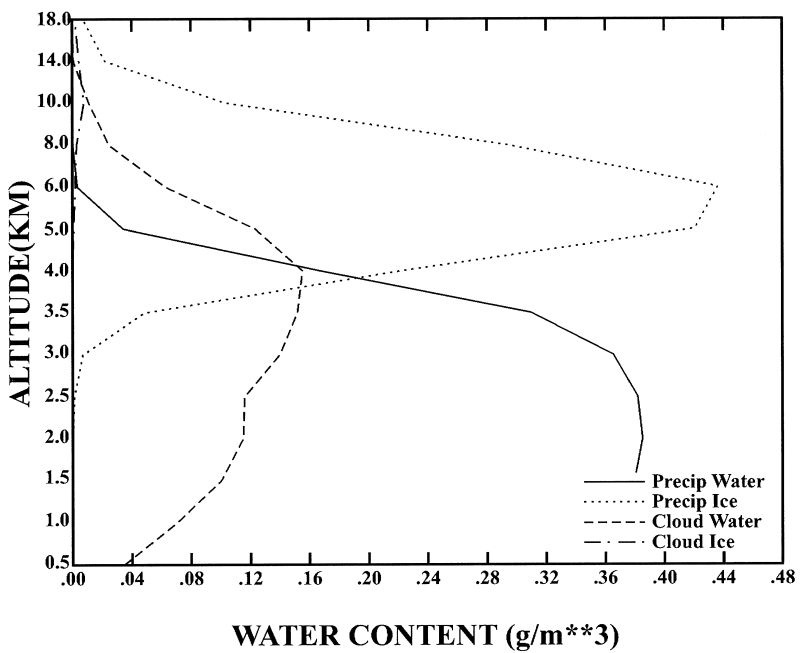

OCEAN NON-LIGHTNING

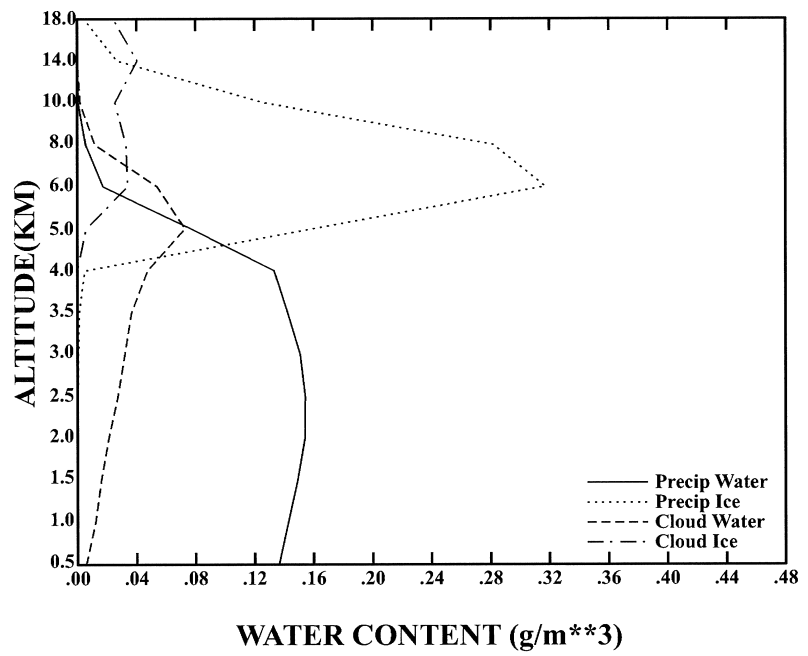

LAND NON-LIGHTNING

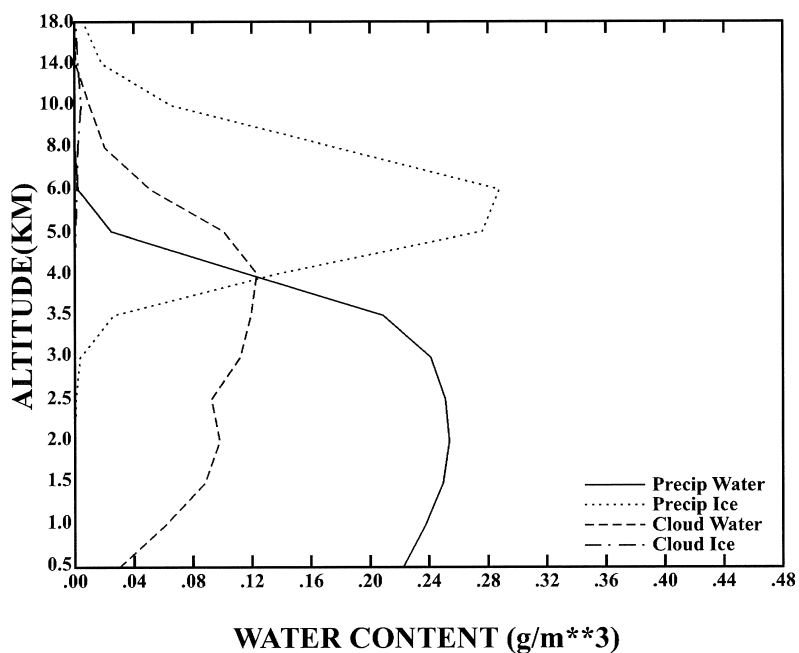

FIG. 4. Hydrometeor vertical profile composites for (upper left) ocean lightning storms, (upper right) ocean nonlightning storms, (lower left) land lightning storms, and (lower right) land nonlightning storms. Note that the vertical resolution degrades upward. Precipitation liquid water (solid), precipitation ice (dotted), cloud liquid water (dashed), cloud ice (dash-dot).

TABLE 3. Mean properties of storms with and without observed lightning.

\begin{tabular}{|c|c|c|c|c|}
\hline & Ocean lightning & Ocean nonlightning & Land lightning & Land nonlightning \\
\hline Surface rain rate $\left(\mathrm{mm} \mathrm{h}^{-1}\right)$ & 4.6 & 0.7 & 6.3 & 1.8 \\
\hline Radius (km) & 64.0 & 14.2 & 30.0 & 10.4 \\
\hline Albedo (\%) & 56 & 31 & 45 & 40 \\
\hline $\operatorname{OLR}\left(\mathrm{W} \mathrm{m}^{-2}\right)$ & 176 & 232 & 173 & 221 \\
\hline Precipitation IWP $\left(\mathrm{g} \mathrm{m}^{-2}\right)$ & 1948 & 1487 & 2377 & 1001 \\
\hline Cloud IWP $\left(\mathrm{g} \mathrm{m}^{-2}\right)$ & 830 & 158 & 49 & 17 \\
\hline Precipitation LWP $\left(\mathrm{g} \mathrm{m}^{-2}\right)$ & 1179 & 242 & 1552 & 687 \\
\hline Cloud LWP $\left(\mathrm{g} \mathrm{m}^{-2}\right)$ & 470 & 60 & 775 & 527 \\
\hline $500-\mathrm{mb}\langle\omega\rangle\left(10^{-1} \mathrm{~Pa} \mathrm{~s}^{-1}\right)$ & -0.32 & -0.22 & -0.31 & -0.17 \\
\hline $850-500-\mathrm{mb} \Delta T(\mathrm{~K})$ & 22.4 & 21.2 & 23.3 & 24.1 \\
\hline 850-mb RH (\%) & 73 & 73 & 73 & 64 \\
\hline 500-mb RH $(\%)$ & 46 & 42 & 53 & 47 \\
\hline
\end{tabular}



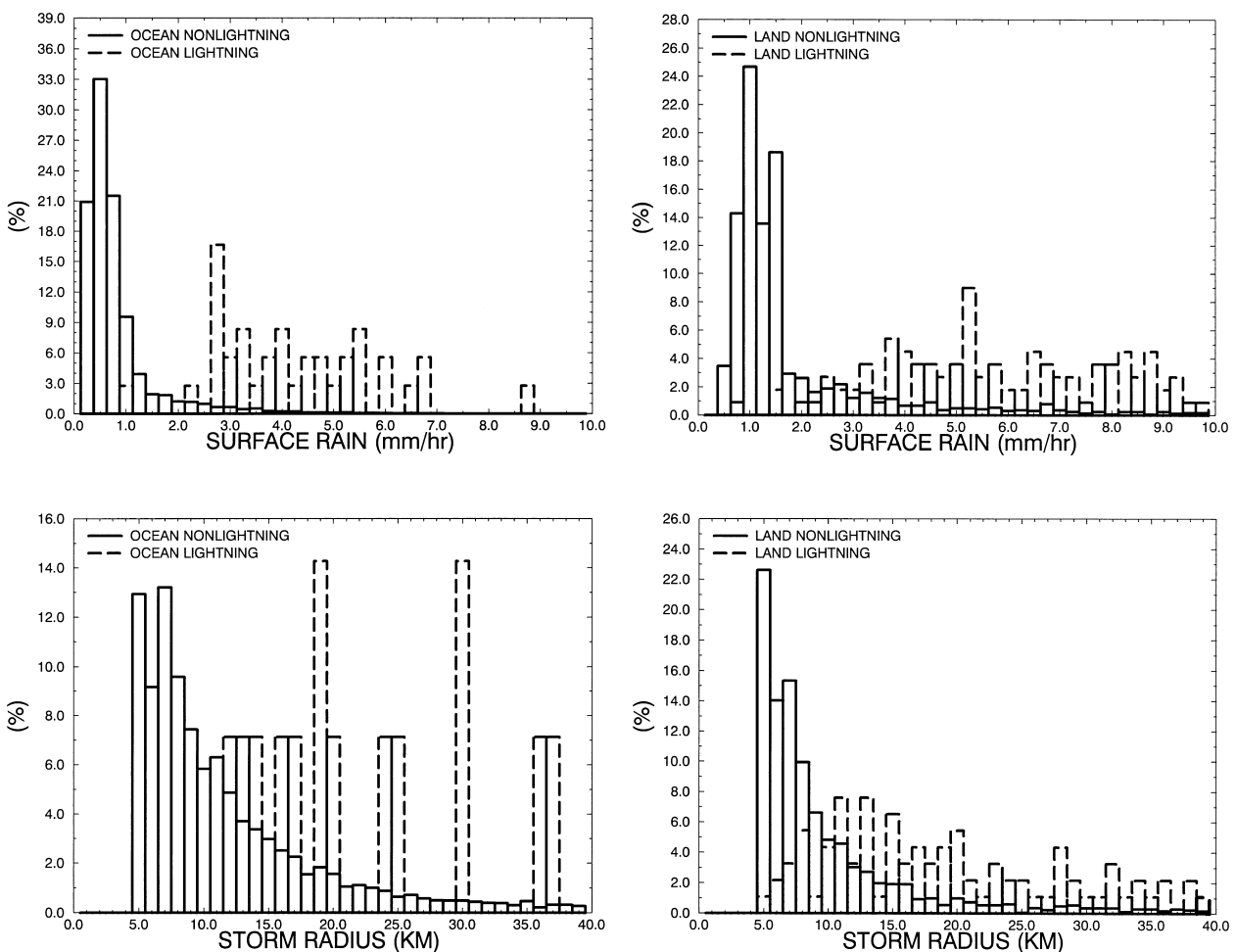

FIG. 5. Normalized histograms of (upper) surface rain rate and (lower) storm radius for (left) ocean lightning and nonlightning storms and (right) land lightning and nonlightning storms.
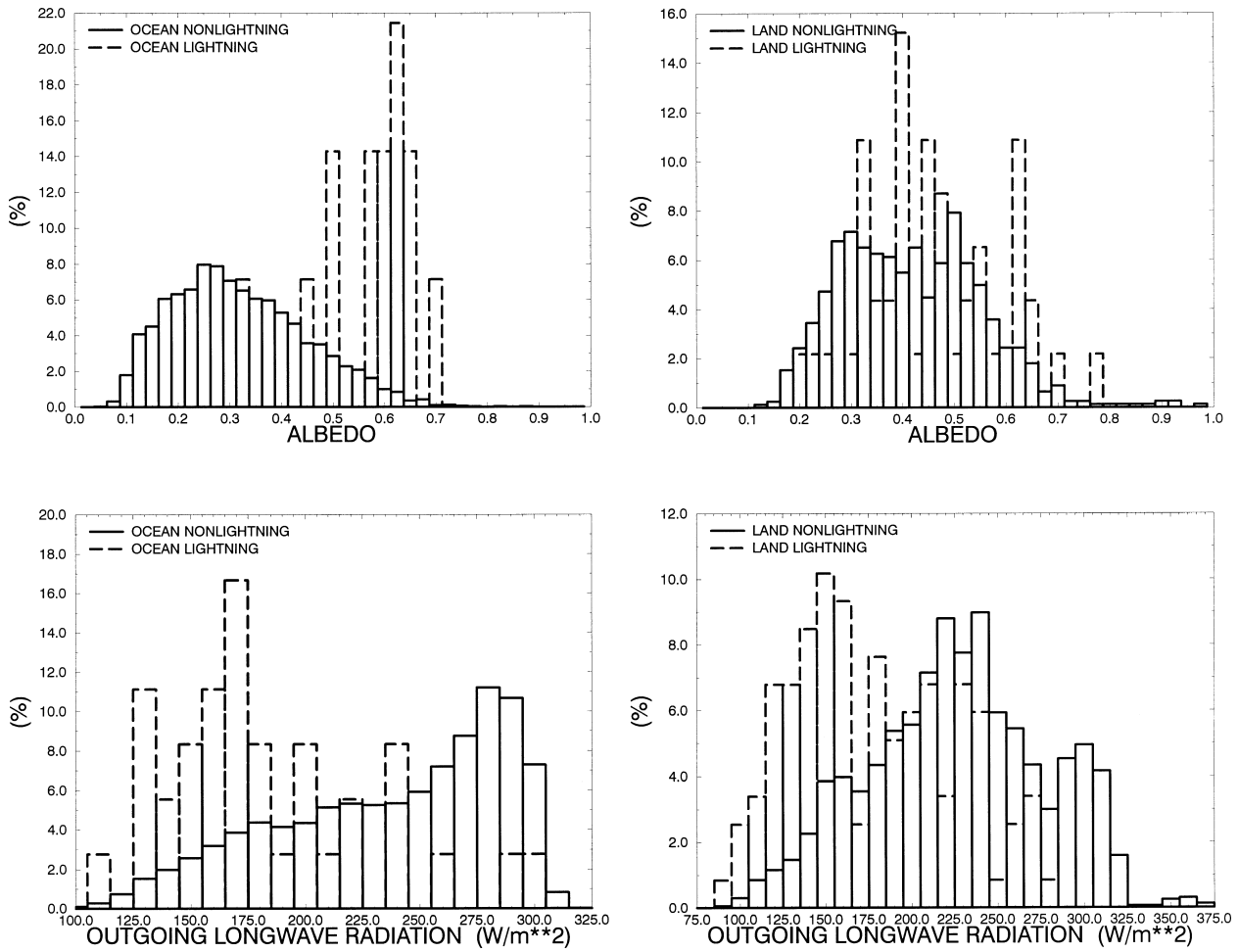

FIG. 6. As in Fig. 5 but for (upper) albedo and (lower) OLR. 

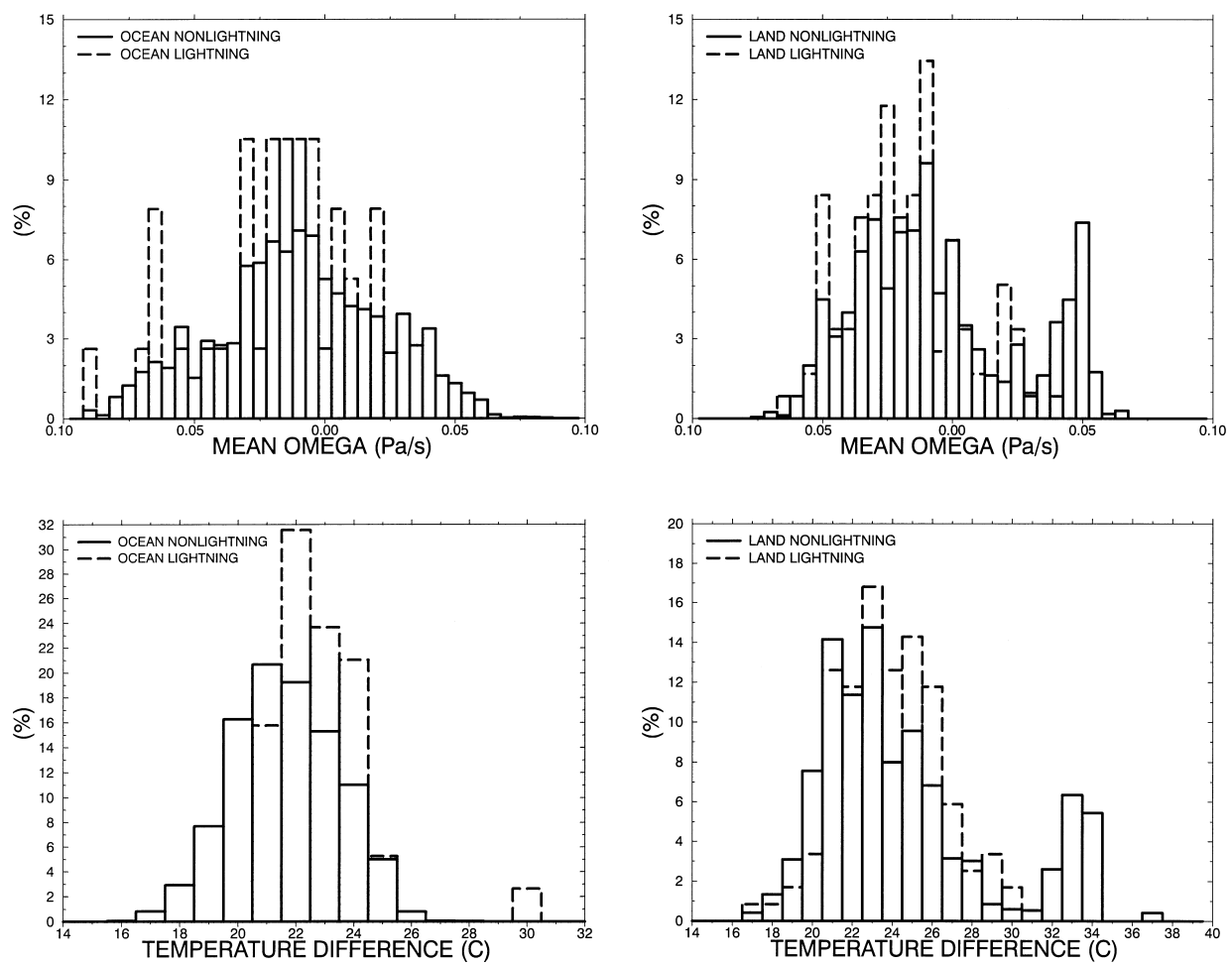

FIG. 7. As in Fig. 5 but for (upper) 500-mb $\langle\omega\rangle$ and (lower) 850-500-mb $\Delta T$.

buoyancy of a rising parcel can be reduced by entrainment of drier air.

Frequency distributions of the large-scale conditions under which different storm types occur are broad and overlap significantly. This is perhaps partly a limitation of the reanalysis products. Nonetheless, some differences appear to exist (Figs. 7 and 8). Lightning storms over both land and ocean tend to occur slightly more often with strong monthly mean upward motion $(\langle\omega\rangle)$ than do nonlightning storms. 850-500-mb temperature differences $\Delta T$ (corresponding to $\sim 4.4-\mathrm{km}$ altitude difference) show clearly a greater occurrence of steeper lapse rates for lightning storms over both ocean and land, but a small secondary population of nonlightning continental storms occurring under steep lapse rates causes the mean nonlightning lapse rate to exceed that for land lightning storms shown in Table 3. The 850mb relative humidities $\left(\mathrm{RH}_{850}\right)$ are similarly distributed for all storm types, except for a secondary population of dry low-level humidity $(<40 \%)$ nonlightning storms over land. These are the same storms that exhibit unusually steep lapse rates, indicating that buoyancy due to the large CAPE of the free troposphere into which these storms grew was offset by the work needed to reach their high lifting condensation levels, thus explaining the absence of lightning production. Relative humidities at $500 \mathrm{mb}\left(\mathrm{RH}_{500}\right)$ are also similarly distributed for the various storm categories, but over both land and ocean there are noticeably fewer occurrences of very dry midlevel humidity $(<30 \%)$ for the lightning cases. This suggests that midlevel entrainment of dry air can have a significant effect on convective updraft speeds.

\section{Environmental influences on storm characteristics}

Since future cloud feedbacks involve a response to a climate warming, it has become common to examine the dependence of cloud properties on SST (cf. Ramanthan and Collins 1991; Lindzen et al. 2001). However, variations in the large-scale dynamics also affect clouds, and since the dynamics is partly tied to the SST pattern, misleading inferences about feedbacks may result from looking at the SST dependence alone. We therefore examine the joint dependence of ocean convective storm properties on SST and $\langle\omega\rangle$. SST and $\langle\omega\rangle$ are themselves correlated (correlation coefficient $r=$ 0.63 , significant at $>99 \%$ ) in the equatorial region. Specifically, downward motion is more prevalent for SST $<27^{\circ} \mathrm{C}$, while upward motion is more common for SST $>28^{\circ} \mathrm{C}$ (see Figs. 9 and 10). But they are sufficiently independent to satisfy collinearity constraints for performing multiple regression analyses.

We average storm properties in $25 \times 25$ bins spanning $\mathrm{SST}=23^{\circ}-31^{\circ} \mathrm{C}$ and $\langle\omega\rangle=-0.1$ to $+0.1 \mathrm{~Pa} \mathrm{~s}^{-1}$. Figures 9 (surface rain rate and storm radius) and 10 (albedo and OLR) show the resulting joint dependence of storm properties on SST and $\langle\omega\rangle$ for all storms and separately for MCSs. Table 4 shows the results of mul- 

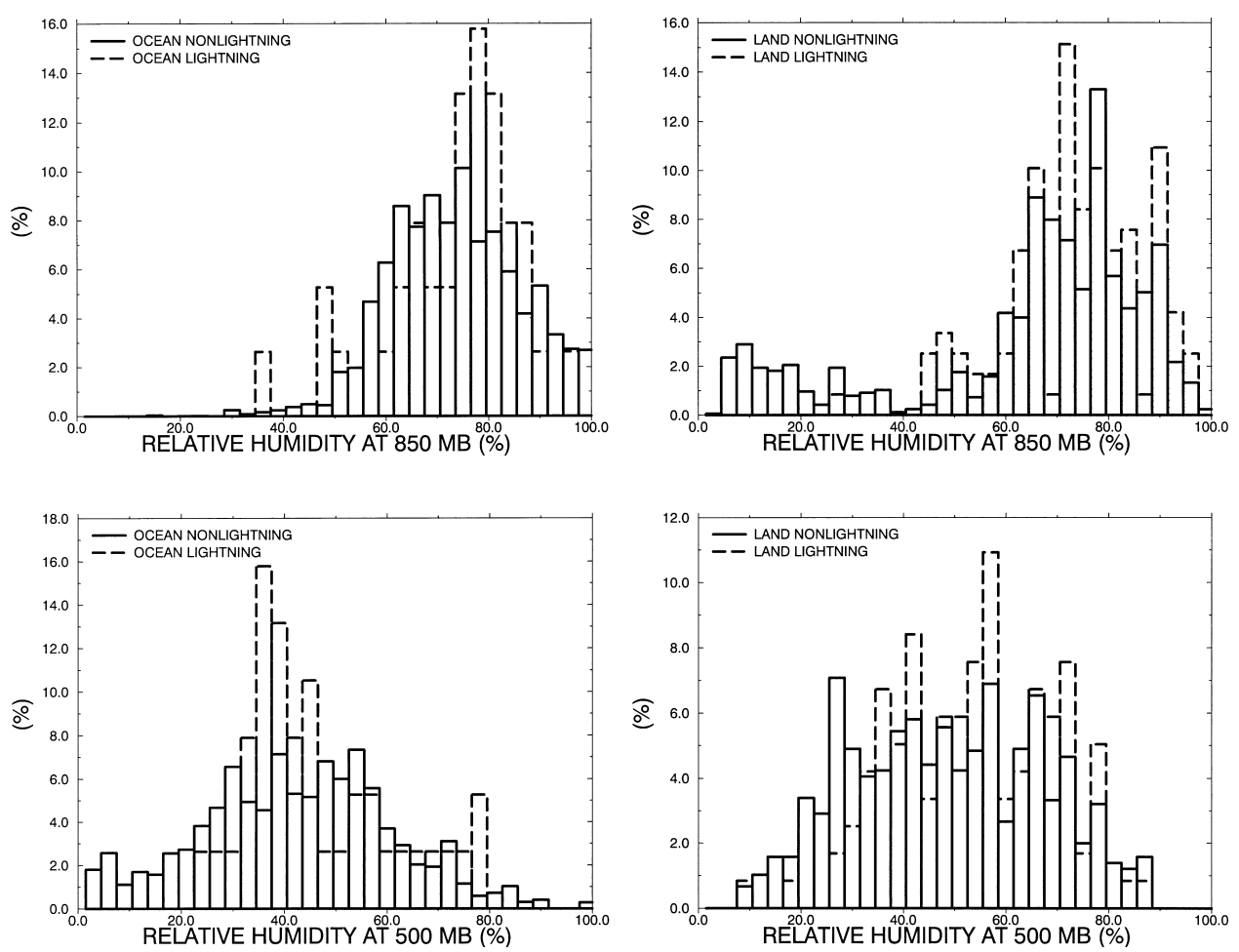

FIG. 8. As in Fig. 5 but for (upper) 850-mb RH and (lower) 500-mb RH.

tiple regression fits to these data. The SST dependence of cloud properties is generally stronger and more statistically significant than their dependence on $\langle\omega\rangle$; the latter is visible in the figures only in the difference between behavior in upward versus downward motion regimes. This may be real or just a limitation of the reanalysis. To assist in the interpretation, we also list in Table 4 the $\pm 95 \%$ confidence intervals for the regression coefficients; coefficients whose confidence interval suggests that at least the sign is correct tentatively though qualitatively indicate how vertical velocity affects cloud properties.

The most obvious feature of Figures 9 and 10 is the distribution of points in SST- $-\omega \omega\rangle$ space; storm occurrence is favored by warm SST and upward motion, a well-known aspect of tropical convection (cf. Fu et al. 1994). Figure 9 shows that surface rain rate increases with SST for all storms, but more dramatically for MCSs $\left(0.6 \mathrm{~mm} \mathrm{~h}^{-1}{ }^{\circ} \mathrm{C}^{-1}\right.$ vs 0.2 for all storms). According to Table 4 , rain rate increases slightly (and marginally significantly) with increasing upward motion for storms in general, and more so (though not statistically significantly) for MCSs. Storms become larger as SST increases, at greater than three times the rate for MCSs as for all storms. Size increases with increasing upward motion for all storms, though not at $95 \%$ significance. Ye (1999), using an objective analysis of a denser sounding network for the west Pacific region than is used in the NCEP-NCAR reanalysis, shows that larger storms originate preferentially in environments with strong upward motion throughout the troposphere and hence moist midlevel humidities that favor penetration of convective elements to the upper troposphere.

Shortwave and longwave properties of storms behave quite differently from each other (Fig. 10, Table 4). Albedos of all storms do not clearly depend on either SST or $\langle\omega\rangle$, and these parameters explain virtually none of the variance in albedo. MCSs, however, become noticeably brighter with warming $\left(5.4 \%{ }^{\circ} \mathrm{C}^{-1}\right)$ but do not significantly depend on vertical velocity; the regressors explain $17 \%$ of the variance for these storms. On the other hand, OLR decreases (i.e., storm tops rise) with warmer SST for all storms, but again about three times as strongly for MCSs as for storms in general. Higher storm tops also correlate with increasing upward motion, but less so for MCSs than for storms in general (perhaps, as suggested by a reviewer, because the anvils associated with the larger storms do not penetrate as high as the convective cores themselves). For MCSs, $55 \%$ of the variance is explained, suggesting that surface conditions predict cloud height better than any other aspect of large storms.

Storms actually respond to instantaneous rather than monthly mean conditions, but the reanalysis instantaneous vertical velocity field is too noisy to be useful. Instead, we examined instantaneous reanalysis fields of thermodynamic variables ostensibly related to vertical velocity. We paired three instantaneous regressors with 


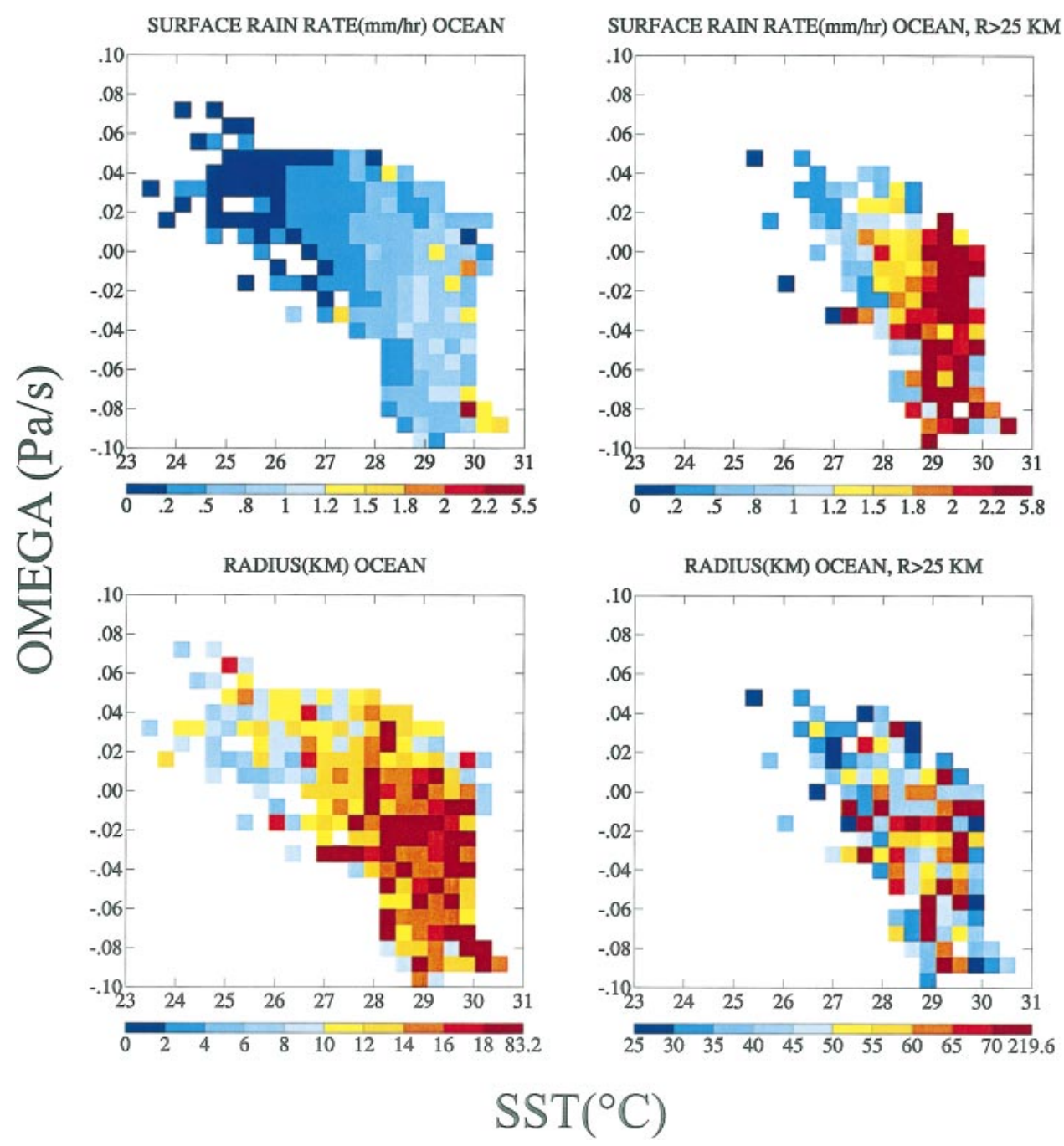

FIG. 9. Binned (upper) surface rain rate and (lower) storm radius as a function of $\langle\omega\rangle$ (ordinate) and SST (abscissa) for (left) all ocean storms and (right) MCSs. Rain-rate and radius values are indicated by the color bars. Only bins that contain at least five storms are included.

SST $\left(\Delta T, \mathrm{RH}_{850}, \mathrm{RH}_{500}\right)$. Of these, $\Delta T(r=0.53)$ and $\mathrm{RH}_{500}(r=0.42)$ are also fairly strongly correlated with SST; $\mathrm{RH}_{850}$ is surprisingly weakly correlated $(r=0.11)$. On the other hand, $\Delta T$ is more closely constrained by data inputs into the reanalysis than are the other three parameters, and despite its correlation with SST, it nonetheless satisfies collinearity constraints for multiple regression. Table 5 shows regression fits for various storm properties against SST and $\Delta T$, SST and $\mathrm{RH}_{850}$, and SST and $\mathrm{RH}_{500}$. Regression coefficients for the SST dependence of all parameters are fairly insensitive to the choice of the second regression variable, suggesting that we have captured the true SST dependence for current climate variability. The small magnitude and change of sign of the SST dependence of albedo depending on the choice of second regression variable confirms that, except for MCSs, convective storm al- bedos are insensitive to SST. OLR depends significantly (95\% confidence) on all of the alternate second regression variables, but the SST dependence is strongest. No other storm property depends in an important way on the second regression variable. Except for OLR, the greatest variance is explained when SST and lapse rate are paired as regression variables.

\section{Discussion}

\section{a. Water budgets of tropical convective storms}

Figure 11 shows surface rain rates as a function of albedo and OLR for land and ocean storms. Ocean storms rain more heavily and become brighter (implying increasing amounts of ice) as their top height increases. Land storms generally exhibit similar behavior, but 


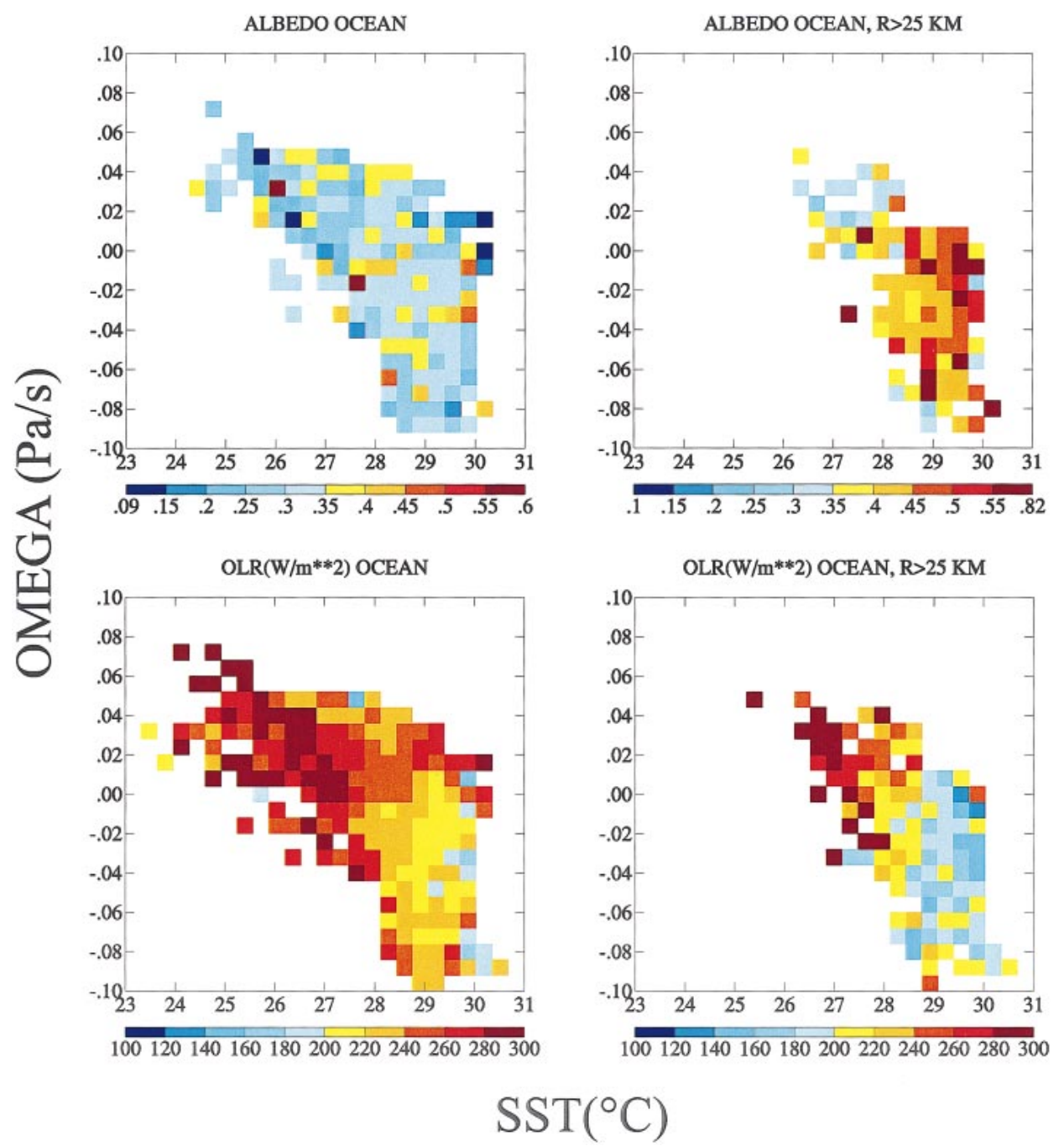

FIG. 10. As in Fig. 9 but for (upper) albedo and (lower) OLR as a function of $\langle\omega\rangle$ and SST.

TABLE 4. Linear regression coefficients $a, b$ and $\pm 95 \%$ confidence intervals for fits to various storm parameters $P(\mathrm{SST},\langle\omega\rangle)=a \mathrm{SST}+$ $b\langle\omega\rangle+c$. Regression coefficients are calculated per ${ }^{\circ} \mathrm{C}$ for SST and per $0.1 \mathrm{~Pa} \mathrm{~s}^{-1}$ for $\langle\omega\rangle$. Also listed is the fractional variance explained $R^{2}$.

\begin{tabular}{|c|c|c|c|c|c|}
\hline & $a$ & $\pm 95 \%$ & $b$ & $\pm 95 \%$ & $\mathrm{R}^{2}$ \\
\hline \multicolumn{6}{|c|}{ Surface rain rate $\left(\mathrm{mm} \mathrm{h}^{-1}\right)$} \\
\hline All storms & 0.17 & $0.22 / 0.12$ & -0.17 & $-0.008 /-0.34$ & 0.35 \\
\hline MCSs & 0.63 & $0.85 / 0.41$ & -0.27 & $0.29 /-0.82$ & 0.34 \\
\hline \multicolumn{6}{|l|}{ Radius (km) } \\
\hline All storms & 1.77 & $2.60 / 0.95$ & -2.26 & $0.65 /-5.18$ & 0.19 \\
\hline MCSs & 6.97 & $12.72 / 1.22$ & 2.28 & $16.69 /-12.12$ & 0.06 \\
\hline \multicolumn{6}{|l|}{ Albedo (\%) } \\
\hline All storms & -0.50 & $0.61 /-1.60$ & -2.80 & $0.68 /-6.29$ & 0.01 \\
\hline MCSs & 5.38 & $8.24 / 2.53$ & 1.81 & $8.50 /-4.88$ & 0.17 \\
\hline \multicolumn{6}{|l|}{$\operatorname{OLR}\left(\mathrm{W} \mathrm{m}^{-2}\right)$} \\
\hline All storms & -10.0 & $-6.9 /-13.2$ & 13.1 & $24.2 / 2.0$ & 0.34 \\
\hline $\mathrm{MCSs}$ & -34.0 & $-26.3 /-41.7$ & 6.2 & $24.7 /-12.4$ & 0.55 \\
\hline
\end{tabular}



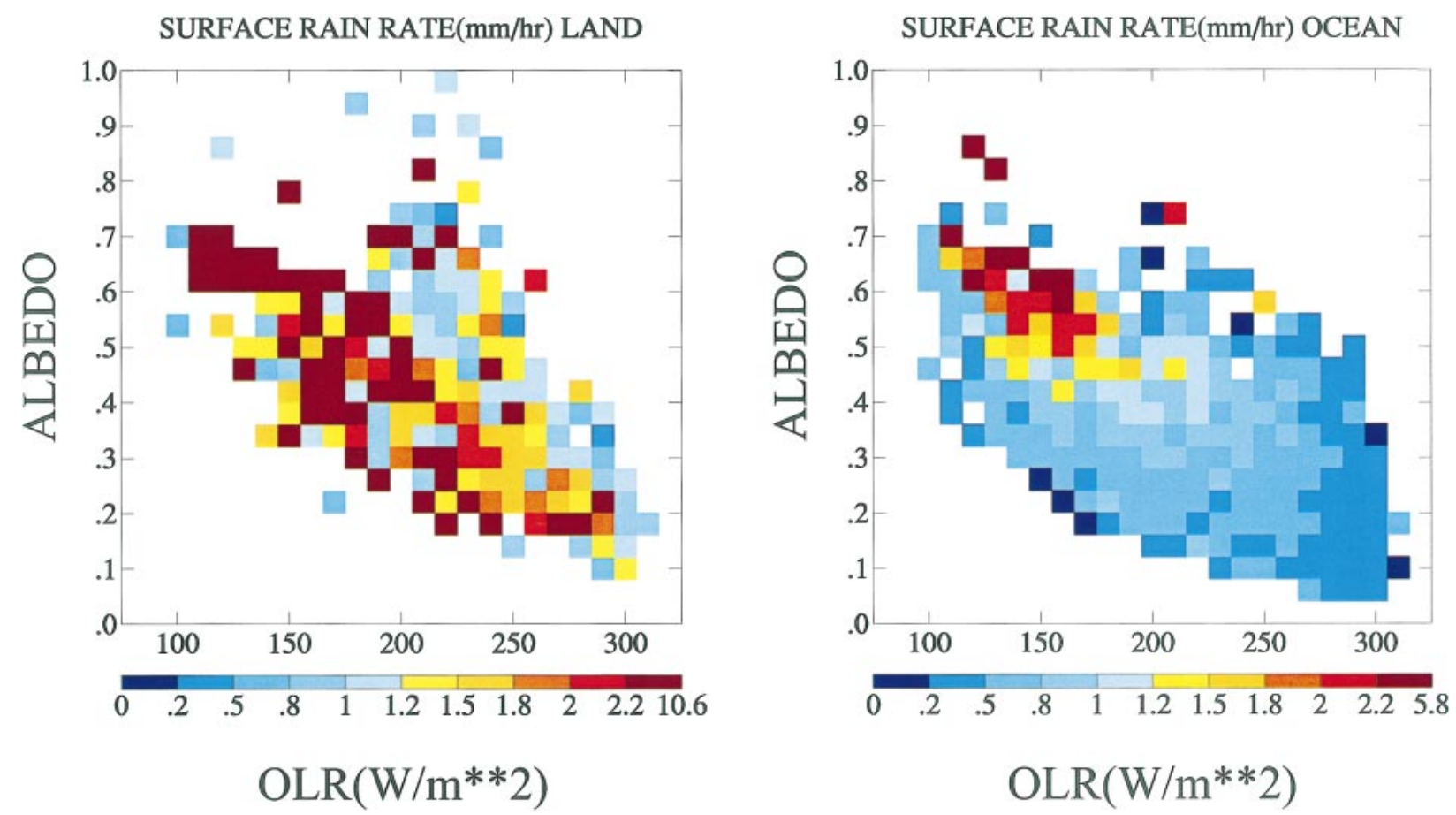

FIG. 11. Binned surface rain rate (indicated by the color bar) as a function of albedo (ordinate) and OLR (abscissa) for (left) land storms and (right) ocean storms.

some very high rain rates are observed in storms with very low albedo and high OLR values as well. In addition, there are two populations of land storms at high albedos: one with strong precipitation and high cloudtop altitude, and a second with low rain rates and modest cloud-top heights $\left(\mathrm{OLR}>185 \mathrm{~W} \mathrm{~m}^{-2}\right)$. The second population is only weakly suggested over ocean. Taken

TABLE 5. Linear regression coefficients $a, b$ for fits to storm parameters $P(\mathrm{SST}, x)=a \mathrm{SST}+b x+c$, where $x=\Delta T$, $\mathrm{RH}_{850}$, or $\mathrm{RH}_{500}$. The regression coefficient $b$ is calculated per ${ }^{\circ} \mathrm{C}$ for lapse rate and per $10 \%$ change for $\mathrm{RH}$. Also listed is the fractional variance explained $R^{2}$.

\begin{tabular}{|c|c|c|c|}
\hline & $a$ & $b$ & $R^{2}$ \\
\hline \multicolumn{4}{|c|}{ Surface rain rate $\left(\mathrm{mm} \mathrm{h}^{-1}\right)$} \\
\hline $\mathrm{SST}-\Delta T$ & 0.15 & 0.013 & 0.57 \\
\hline SST-RH $\mathrm{RH}_{850}$ & 0.19 & -0.0074 & 0.37 \\
\hline SST-RH $\mathrm{R}_{500}$ & 0.18 & -0.0094 & 0.46 \\
\hline \multicolumn{4}{|l|}{ Radius (km) } \\
\hline $\mathrm{SST}-\Delta T$ & 1.93 & 0.20 & 0.29 \\
\hline SST-RH $\mathrm{RH}_{850}$ & 2.04 & -0.14 & 0.22 \\
\hline SST-RH $\mathrm{R}_{500}$ & 1.82 & 0.25 & 0.16 \\
\hline \multicolumn{4}{|l|}{ Albedo (\%) } \\
\hline $\mathrm{SST}-\Delta T$ & -0.37 & 0.067 & 0.06 \\
\hline SST-RH ${ }_{850}$ & 0.38 & 0.019 & 0.01 \\
\hline SST-RH $\mathrm{R}_{500}$ & -0.79 & 0.040 & 0.02 \\
\hline \multicolumn{4}{|l|}{$\operatorname{OLR}\left(\mathrm{W} \mathrm{m}^{-2}\right)$} \\
\hline $\mathrm{SST}-\Delta T$ & -7.8 & -3.0 & 0.29 \\
\hline SST-RH ${ }_{850}$ & -10.3 & -3.3 & 0.27 \\
\hline $\mathrm{SST}-\mathrm{RH}_{500}$ & -10.6 & -3.8 & 0.33 \\
\hline
\end{tabular}

together, the result is a tendency for land storms of moderate height to increase their albedos at the expense of precipitation, as opposed to the ocean tendency for albedo and rain rate to increase together.

This behavior is restricted to OLR $>185 \mathrm{~W} \mathrm{~m}^{-2}$ (cloud-top temperatures $>-35^{\circ} \mathrm{C}$ ), inviting speculation that these storms are not fully (or even partially) glaciated. The continental boundary layer has higher aerosol concentration than the maritime boundary layer. Case studies (Rosenfeld and Woodley 2000) and microphysical modeling (Khain et al. 2001) suggest that the resulting large concentration of small supercooled droplets will inhibit coalescence growth and precipitation, and reduce the probability of immersion/contact freezing. Once the cloud penetrates below the $-39^{\circ} \mathrm{C}$ threshold for homogeneous nucleation, glaciation is inevitable and the added buoyancy carries the updraft several kilometers higher, more water condenses, and mixed-phase processes dramatically increase the rain rate. This might explain the existence of two separate populations and the absence of storms with OLR between 150 and $180 \mathrm{~W} \mathrm{~m}^{-2}$.

The positive correlation between rain rate and albedo for ocean storms in Fig. 11 must be reconciled with Table 4, which indicates that rain rate responds strongly to surface warming but albedo generally does not. The frequency distribution of albedos and rain rates at a given SST is broad, with the more heavily precipitating storms tending to be brighter. Both distributions are 

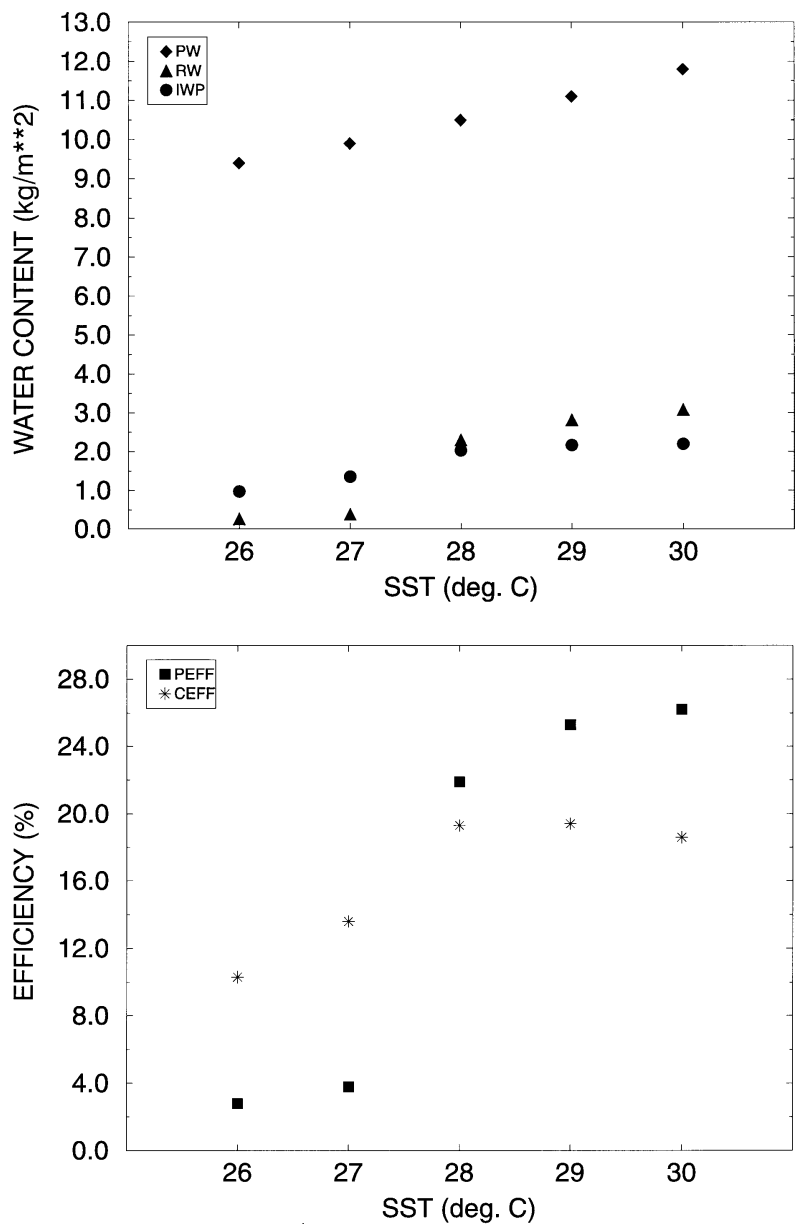

FIG. 12. Ocean storm area-weighted water budget indices composited at $1^{\circ} \mathrm{C} \mathrm{SST}$ intervals: (upper) $\mathrm{PW}, \mathrm{RW}$, and IWP $\left(\mathrm{kg} \mathrm{m}^{-2}\right)$, (lower) PEFF and CEFF (\%).

skewed, but rain rate much more so (Figs. 5, 6). As SST increases, the distribution of albedo broadens by $\sim 20 \%$ while the standard deviation of the rain-rate distribution broadens by an order of magnitude. This causes a slight increase in mean albedo but a large increase in mean rain rate, which is inordinately weighted by the few storms with the heaviest rain rates.

Assuming that convection originates from roots in a mixed layer of depth $z_{m}=500 \mathrm{~m}$ with specific humidity $q$ defined by a surface value at $80 \%$ relative humidity in air $1^{\circ} \mathrm{C}$ colder than the surface, we define an available precipitable water vapor (in $\mathrm{kg} \mathrm{m}^{-2}$ ) as $\mathrm{PW}=q \rho z_{m}$, where $\rho$ is air density. The surface rain rate in $\mathrm{mm} \mathrm{h}^{-1}$ equals the rainwater (RW) that falls in $1 \mathrm{~h}$, and the ice water path (IWP) is an estimate of suspended anvil condensate. We then define a precipitation efficiency index $\mathrm{PEFF}=100 \mathrm{RW} / \mathrm{PW}$ as the percentage of available water vapor that precipitates per hour at the observed rain rate, and a cloud efficiency index $\mathrm{CEFF}=100$ IWP/PW as the percentage of available water vapor that forms the anvil cloud. These are only qualitative indices based on a snapshot of a given storm, but their behavior indicates how the water budgets of tropical convective storms behave in different environments.

Figure 12 shows area-weighted values of PW, RW, IWP, PEFF, and CEFF for ocean storms binned in $1{ }^{\circ} \mathrm{C}$ SST increments. For constant relative humidity, PW increases with SST according to the Clausius-Clapeyron equation. TMI rain amounts and ice water paths also increase monotonically with SST, the largest increase occurring at $28^{\circ} \mathrm{C}$ as strong upward motion becomes prevalent. Precipitation efficiency systematically increases with SST, while cloud efficiency increases at the low end of the SST range but levels off and perhaps even slightly decreases at the warmest SSTs. The fraction of updraft water going into detrained ice rather than precipitation thus peaks at the lower SSTs and decreases at higher SST. Thus, at high SST a limit is reached on how much ice can be suspended in the column per unit area, and additional water vapor goes into rain formation. However, as we show later, additional cloud ice forms instead as greater cloud area.

\section{b. Implications for cumulus parameterization in climate models}

Most cumulus parameterization research to date has emphasized triggering conditions and mass flux closures. Details of condensate transport by convective updrafts and downdrafts, which control the radiative properties of convective cloud systems and thus the convective contribution to cloud feedback, have been virtually ignored. The results presented in this paper provide a means for testing and improving this neglected aspect of parameterized convection.

Schemes that predict mass fluxes make ad hoc assumptions about the fraction of condensed water in updrafts that is converted to precipitation, since GCMs do not calculate droplet size distributions. Figures 11 and 12 suggest that precipitation efficiency and vertical condensate transport are variable, yet are sufficiently well behaved to be parameterized as a function of a limited number of parameters. For schemes that predict updraft strengths, additional constraints are provided by our segregation of storm cloud properties by lightning occurrence. Since the threshold mean updraft speed for lightning is $\sim 6-7 \mathrm{~m} \mathrm{~s}^{-1}$ (Zipser and Lutz 1994), models that calculate updraft speed can be subjected to several observational tests: the fraction of storms with updrafts above the threshold and the difference in this fraction among land and ocean storms (Table 2); rain rates, albedos, and cloud-top heights for lightning versus nonlightning storms (Figs. 5, 6); and environmental conditions differentiating lightning and nonlightning storms (Figs. 7, 8). Finally, we note that recently, cumulus parameterizations have begun to diagnose mesoscale motions (cf. Donner et al. 2001). Our results (Figs. 1-3) and those of Machado et al. (1998) and Ye (1999) show that most convection exists as isolated cells, that rainfall 

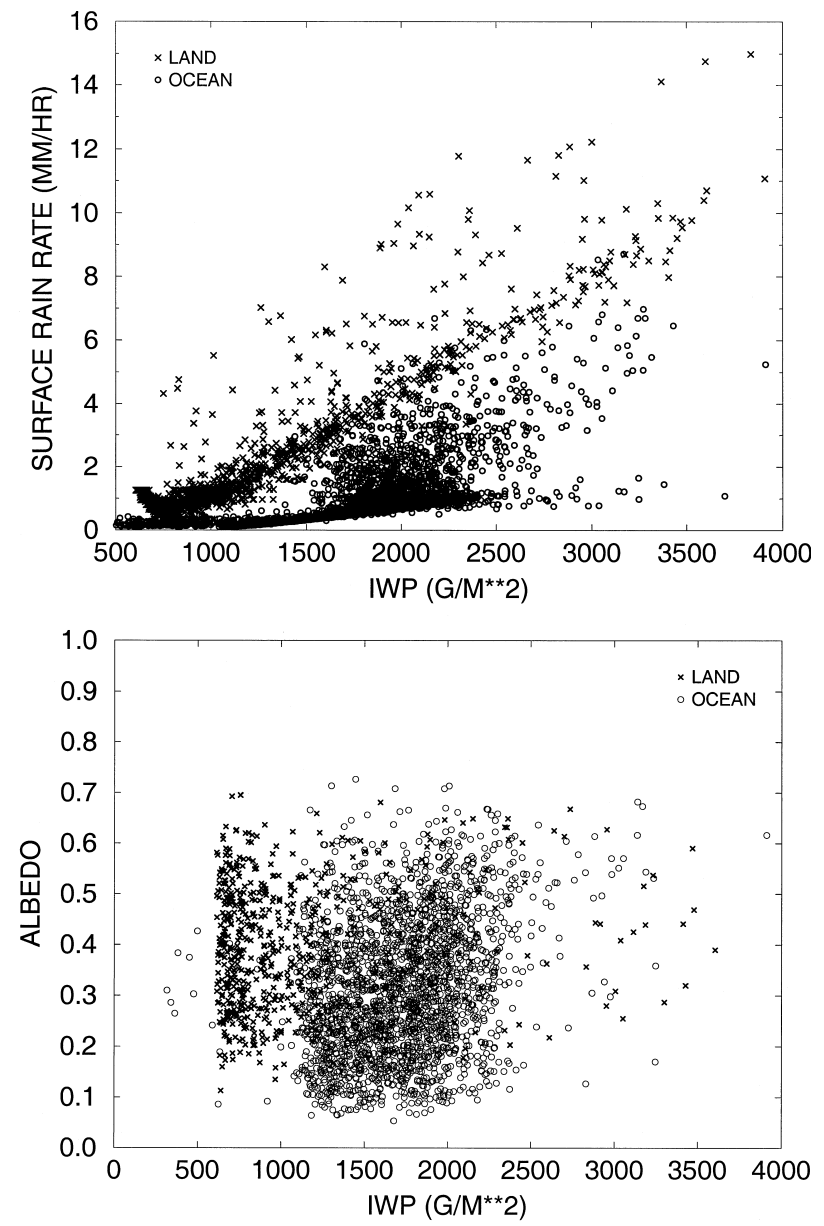

FIG. 13. (upper) Surface rain rate and (lower) albedo as a function of IWP for land $(X)$ and ocean storms $(\bigcirc)$. Only storms observed at solar zenith angles $<30^{\circ}$ are included in the lower panel. Random errors in instantaneous fluxes due to the angular distribution model used for the CERES ES-8 product introduce scatter in the estimated albedo of about \pm 0.05 .

from these small storms cannot be completely neglected, and that the radiative effects of small storms are competitive with those of MCSs. Thus, cumulus parameterizations must allow for mesoscale effects as an option but not a feature of all convection.

Increasingly, CRMs are being asked to play a role in the GCM cloud parameterization problem. The basic premise of the Global Energy and Water Cycle Experiment (GEWEX) Cloud System Study is that CRMs are sufficiently realistic to guide parameterization of cloud processes that cannot be observed. Khairoutdinov and Randall (2001) use a CRM in place of the cloud and convection parameterizations in a GCM, the implication being that the more realistic representation of smallscale dynamics in the CRM will give a more credible estimate of things like cloud feedback.

The TMI 2A-12 product includes hydrometeor profiles derived from CRM simulations constrained by ob-
TABLE 6. Visible optical thicknesses predicted from the mean values of precipitation ice (PI), cloud ice (CI), precipitation liquid (PL), and cloud liquid (CL) water path in Table 3 for assumed effective radii given in the text. Also shown for comparison are the resulting total optical thickness and observed shortwave albedos for each storm category.

\begin{tabular}{lcccc}
\hline \hline & $\begin{array}{c}\text { Ocean } \\
\text { lightning }\end{array}$ & $\begin{array}{c}\text { Ocean } \\
\text { nonlightning }\end{array}$ & $\begin{array}{c}\text { Land } \\
\text { lightning }\end{array}$ & $\begin{array}{c}\text { Land } \\
\text { nonlightning }\end{array}$ \\
\hline$\tau_{\mathrm{P} 1}$ & 28.2 & 21.5 & 34.4 & 14.5 \\
$\tau_{\mathrm{Cl}}$ & 70.1 & 13.3 & 4.1 & 1.4 \\
$\tau_{\mathrm{PL}}$ & 1.8 & 0.4 & 2.4 & 1.0 \\
$\tau_{\mathrm{CL}}$ & 35.2 & 4.5 & 58.1 & 39.5 \\
$\tau_{\text {TOTAL }}$ & 135.3 & 39.7 & 99.0 & 56.4 \\
Albedo & 56 & 31 & 45 & 40 \\
\hline
\end{tabular}

served microwave radiances. Since CERES data are not used, observed shortwave albedos provide an independent test of the realism of the CRM hydrometeor column amounts. Figure 13 shows the $2 \mathrm{~A}-12$ surface rain rate (upper) and CERES albedo (lower) as a function of the $2 \mathrm{~A}-12$ total IWP for each of our observed storms. There are clear relationships between rain and IWP over both land and ocean. However, the albedo-IWP relationship is not statistically significant over land (correlation $r=$ $0.1)$ and significant but a poor predictor $(r=0.3)$ over ocean. Some scatter is expected, since different storms have different relative amounts of small and large particle ice. Furthermore, for land storms, cloud liquid water is the dominant contributor to albedo, as we will subsequently show. But for ocean storms, in which ice mass dominates the contribution to reflected sunlight, the correlation between IWP and albedo is quite weak. Heymsfield and McFarquhar (1996), by comparison, find a strong correlation between ice content and cloud extinction for aircraft-observed anvils. Furthermore, Fig. 4 shows no evidence of observed differences in hydrometeor vertical structure between lightning and nonlightning storms. It therefore seems that CRMs have limited predictive capability for cloud microphysical structure and reflected sunlight in individual cases. The cloud feedback predictions of such models must therefore be viewed with caution.

CRMs are better predictors of mean storm properties. Table 3 and Fig. 6 show that lightning storms are brighter than nonlightning storms and that the albedo difference is very large for ocean storms but much smaller for land storms. To see whether the 2A-12 water paths are consistent with these differences, we estimate an optical thickness $\tau$ for each hydrometeor type. For liquid clouds, we assume $\tau=1.5 \mathrm{LWP} / r_{e}$, where $r_{e}$ is the effective radius of the droplet size distribution in $\mu \mathrm{m}$ and LWP is in $\mathrm{g} \mathrm{m}^{-2}$. For ice clouds, following Ebert and Curry (1992), we use $\tau=\operatorname{IWP}\left(3.44 \times 10^{-3}+\right.$ $\left.2.431 / r_{e}\right)$. Effective radii for precipitating ice and cloud ice are estimated as 220 and $30 \mu \mathrm{m}$, respectively, by comparing the altitudes (and temperatures) at which each type peaks in Fig. 4 to observations of $r_{e}$ for dif- 
ferent temperatures (Heymsfield and McFarquhar 1996). For liquid, we assign effective radii of $1000 \mu \mathrm{m}$ for precipitating droplets and $20 \mu \mathrm{m}$ for cloud droplets, typical of the upper limits observed in precipitating clouds.

Table 6 shows the optical thickness for each hydrometeor class by storm category, the implied total optical thickness, and the observed albedo. CRM-generated water paths do predict qualitatively that ocean lightning storms are the most reflective and ocean nonlightning storms the least reflective, with land storms intermediate. The extreme brightness of ocean lightning storms is consistent with the CRMs' predictions of large cloud ice contents for these storms. Quantitatively, though, the results are less compelling. According to Heymsfield et al. (1998), for $\tau>40$ albedo is $\sim 50 \%-60 \%$ and fairly independent of optical thickness for a variety of size distributions and particle shapes. The large albedo differences we observe for the different storm types would require TRMM land storms and ocean nonlightning storms to have $\tau \sim 10-20$ instead. These discrepancies are larger than can be explained by cloud water inhomogeneity effects or ERBE angle model errors. It thus seems that the CRMs in the TRMM 2A-12 database overestimate hydrometeor mass. We conclude that CRMs should be used by GCM developers primarily for insights into cumulus dynamics rather than to infer cloud feedback directly.

\section{c. Implications for cloud feedback}

It is not advisable to use current climate variability as a direct proxy for long-term cloud feedback due to convection because the temperature dependence includes effects of variable vertical velocity, relative humidity, and shear, and because of the very different nature of changes in the temperature structure on short and long timescales. On timescales from synoptic to interannual and perhaps even decadal (Gaffen et al. 2000) associated with internal variability of the climate system, warming tends to be greatest at low levels. This occurs because such warmings are regional and induce circulation responses that redistribute temperature anomalies above the trade inversion to other geographic locations. Thus, lapse rate tends to increase with surface warming (cf. the 0.53 correlation between SST and $\Delta T$ we reported earlier), which implies stronger convection. In a long-term radiatively forced equilibrium climate change, for example, due to increasing greenhouse gas concentrations, on the other hand, temperature anomalies are global, circulation responses are more subtle, and reduced longwave cooling of the upper troposphere combined with greater convective heating cause the tropical upper troposphere to warm more than the surface, reducing the lapse rate by an amount comparable to the change in the moist adiabatic lapse rate (cf. Yao and Del Genio 1999). It is not obvious that moist con- vection in such a climate should be "stronger" in any sense but increased precipitation and cloud-top height.

Two factors suggest, though, that convection strength should slightly increase in a forced climate warming. 1) Ye et al. (1998) show that despite the absence of any increase in CAPE due to the change in lapse rate, CAPE nonetheless increases slightly in a climate warming due to a greater contribution of water vapor to parcel virtual temperature. For a $2^{\circ} \mathrm{C}$ warming, they predict a CAPE increase $\sim 20 \%$ of that implied by observed current climate variability. 2) Since climate forcing varies faster than the climate system responds, real climate changes never reach equilibrium; the state at any given time is a transient that is still responding to the existing climate forcing. Thus, upper-tropospheric response may lag a forced surface change. If so, the SST dependences in Table 4 may indicate the direction (but overestimate the magnitude) of the convective response to warming.

The results of this paper do allow us, though, to evaluate the opposing thermostat and adaptive iris views of convective feedback. The adaptive iris hypothesis (clouds thinning with warming) is clearly not supported by the TRMM data. TRMM storms become larger and cover a greater fractional area (Fig. 14), and the largest of them become somewhat brighter, at higher SST. Several flaws in reasoning lead Lindzen et al. (2001) to their conclusion. Their fixed brightness temperature threshold for defining storm area $(<260 \mathrm{~K})$ implies that fewer points will be below $260 \mathrm{~K}$ if the atmosphere warms, independent of actual cloud changes. Their result of cloud area decreasing with SST over $\pm 30^{\circ}$ latitude is contaminated by dynamical clearing of cloud that takes place in the subsidence regions of the subtropics (Hartmann and Michelsen 2002). When they consider only the equatorial region they find, as we do, that stratiform and convection area both increase with SST (though this is partly a function of vertical velocity as well, in the opposite sense). Lindzen et al. emphasize that the ratio of stratiform to convection area still decreases as SST increases. Our results indicate similar behavior: precipitation efficiency increases faster when going from low to high SST than does cloud efficiency (Fig. 12), so in a relative sense, storms put more of their available water into rain than cloud at warmer temperature. In an absolute sense, though, ice water path increases monotonically with SST as cloud efficiency levels off, that is, the fraction of available water vapor going into cloud ice per unit area stabilizes at the warmest temperatures but the absolute amount of cloud material is greater because the available water vapor is greater. This is what determines the feedback. Lin et al. (2001) further show that when CERES-derived radiative parameters are used in the adaptive iris model, a cloud area decrease actually implies weak warming.

The data analysis supporting the thermostat hypothesis (Ramanathan and Collins 1991) mostly reveals the effects of shifts in the tropical circulation rather than any fundamental dependence on SST (cf. Fu et al. 1992). 

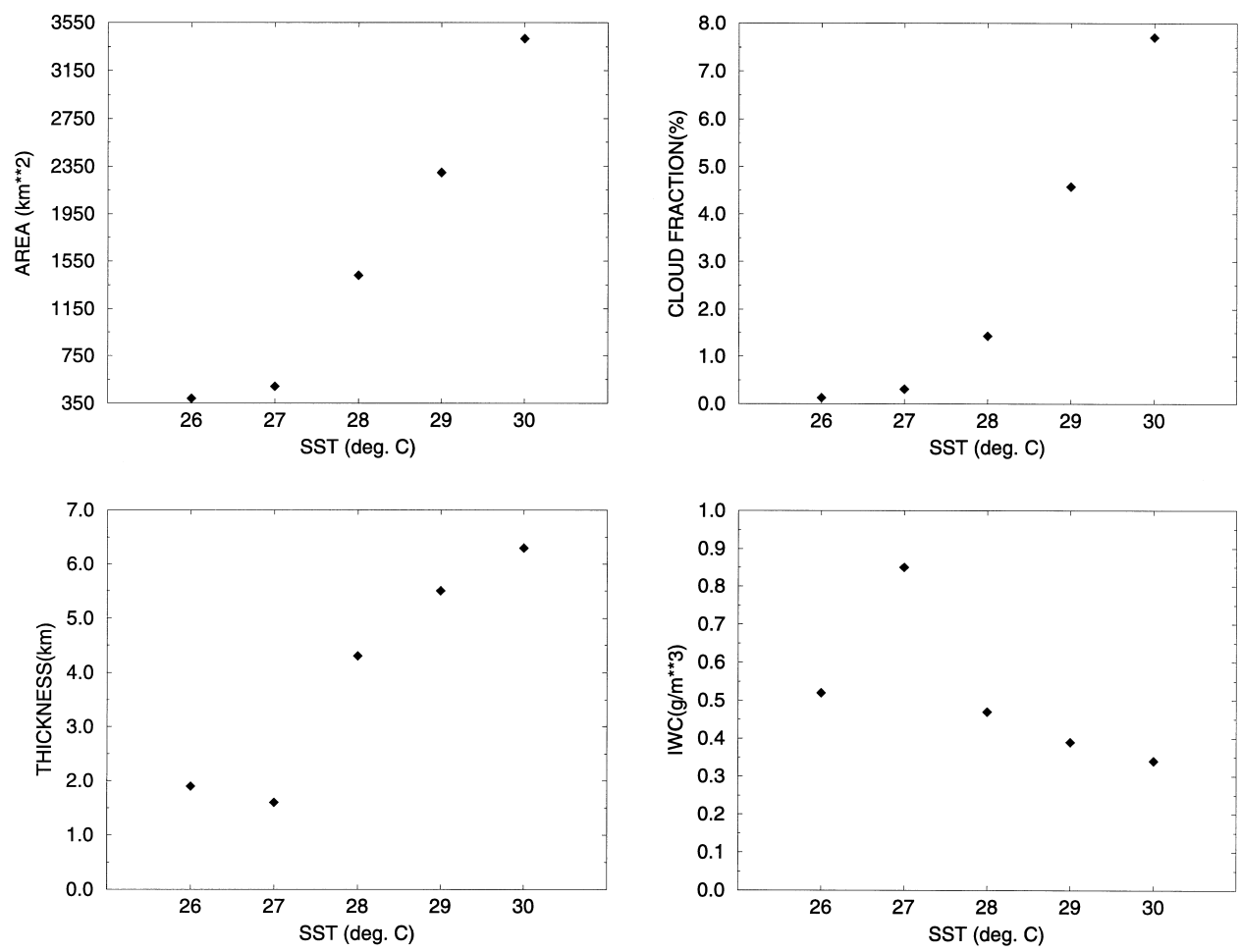

FIG. 14. Ocean storm cloud properties composited at $1^{\circ} \mathrm{C}$ SST intervals. (upper left) Mean storm area $\left(\mathrm{km}^{2}\right)$. (upper right) Cloud fractional coverage (\%). (lower left) Area-weighted anvil thickness (km). (lower right) Area-weighted ice water content $\left(\mathrm{g} \mathrm{m}^{-3}\right)$.

Our results (Tables 4 and 5) isolate the actual SST dependence from the dynamics dependence, to the extent possible with the reanalysis products. Storm radius and cloud fractional coverage increase with SST, for all storms and even more strongly for MCSs. Storm cloud albedo, on the other hand, increases with SST only for the larger storms. However, the actual shortwave feedback is likely to be weaker than that inferred by Ramanathan and Collins (1991) because of the vertical velocity dependence of their results and because current climate variability overstates the climate increase in convection strength.

We also estimate the variation of storm height with SST by converting OLR to a blackbody temperature and assuming that this is roughly indicative of the actual cloud-top temperature. A typical tropical ocean temperature profile is then used to convert this to cloud-top height. Assuming that anvils make up most of the raining area and have bases at the freezing level and ignoring the temperature dependence of freezing height in the equatorial region, we can then estimate how anvil physical thickness $H_{\text {anv }}$ varies with SST. The 2A-12 ice water paths can then be used to derive a mean ice water content IWC $=\mathrm{IWP} / H_{\mathrm{anv}}$. Figure 14 indicates that anvils grow thicker as cloud tops rise at higher SSTs, while IWC increases with SST at relatively cool temperatures but decreases with SST under warmer conditions. Thus, increasing precipitation efficiency with warming begins to dilute anvil ice content, but this is offset by the increased vertical development of the cloud, so that IWP approaches an upper limit at the warmest temperatures. Higher cloud tops at higher SST suggests a positive longwave cloud feedback due to convection. We have not quantified the net cloud feedback, though, since we do not include the nonprecipitating optically thinner clouds associated with the storms and thus overstate the shortwave feedback compared to the storm as a whole. We also note that if Fig. 11 implies an aerosol indirect effect on convective cloud-top height, this would be a new type of negative feedback, since similar albedos would occur in conjunction with lowering cloud-top heights.

The most prudent use of the results presented in this paper would be as a validation standard for a cumulus parameterization's response to current climate variability. The climate modeling community has not yet defined observational metrics for narrowing the uncertainty in climate sensitivity. Comparisons of model-simulated monthly mean global precipitation and cloud forcing maps to observations have clearly not led to a convergence of estimates of cloud feedback. Our results reveal some but not all of the factors controlling the properties of convective systems; the potentially important effects of wind shear, for example, have not been explored. We suggest, however, that if a subset of models can be found whose statistics of convective storm 
properties are consistent with the parameter dependences presented in this paper, an important step will have been taken toward understanding future climate change.

Acknowledgments. We thank M. Jensen for helpful discussions, J. Jonas for providing fields from the NCEP-NCAR reanalysis, S. Menon for assistance with statistical analysis software, L. del Valle for graphics assistance, and two reviewers for insightful comments. TMI and CERES data were obtained from the NASA Goddard and NASA Langley DAACs, respectively. LIS data were obtained from the NASA Marshall Global Hydrology and Climate Center. This research was supported by the NASA Tropical Rainfall Measuring Mission.

\section{REFERENCES}

Adler, R. F., H.-Y. M. Yeh, N. Prasad, W.-K. Tao, and J. Simpson, 1991: Microwave simulations of a tropical rainfall system with a three-dimensional cloud model. J. Appl. Meteor., 30, 924-953.

Boccippio, D. J., S. J. Goodman, and S. Heckman, 2000: Regional differences in tropical lightning distributions. J. Appl. Meteor., 39, 2231-2248.

Christian, H. J., 1999: Optical detection of lightning from space. Proc. 11th Int. Conf. on Atmospheric Electricity, Guntersville, AL, NASA, NASA/CP-1999-209261, 715-718.

Del Genio, A. D., 2001: GCM simulations of cirrus for climate studies. Cirrus, D. K. Lynch, Ed., Oxford University Press, 310326.

_, M.-S. Yao, W. Kovari, and K. K.-W. Lo, 1996: A prognostic cloud water parameterization for global climate models. J. Climate, 9, 270-304.

Donner, L. J., C. J. Seman, and R. S. Hemler, 2001: A cumulus parameterization including mass fluxes, convective vertical velocities, and mesoscale effects: Thermodynamic and hydrological aspects in a general circulation model. J. Climate, 14, 3444 3463.

Ebert, E. E., and J. A. Curry, 1992: A parameterization of ice cloud optical properties for climate models. J. Geophys. Res., 97, 3831-3836.

Fu, R., A. D. Del Genio, and W. B. Rossow, 1990: Behavior of deep convective clouds in the tropical Pacific deduced from ISCCP radiances. J. Climate, 3, 1129-1152.

$-, \ldots,-$, and W. T. Liu, 1992: Cirrus cloud thermostat for tropical sea surface temperatures tested using satellite data. $\mathrm{Na}$ ture, 358, 394-397.

,-- , and — 1994: Influence of ocean surface conditions on atmospheric vertical thermodynamic structure and deep convection. J. Climate, 7, 1092-1108.

Gaffen, D. J., B. D. Santer, J. S. Boyle, J. R. Christy, N. E. Graham, and R. J. Ross, 2000: Multidecadal changes in the vertical temperature structure of the tropical troposphere. Science, 287, $1242-1245$.

Gamache, J. F., and R. A. Houze Jr., 1983: Water budget of a mesoscale convective system in the tropics. J. Atmos. Sci., 40, $1835-1850$

Gregory, D., 2001: Estimation of entrainment rate in simple models of convective clouds. Quart. J. Roy. Meteor. Soc., 127, 53-72.

Hartmann, D. L., and M. L. Michelsen, 2002: No evidence for iris. Bull. Amer. Meteor. Soc., 83, 1233-1238.

Heymsfield, A. J., and G. M. McFarquhar, 1996: High albedos of cirrus in the Tropical Pacific warm pool: Microphysical interpretations from CEPEX and from Kwajalein, Marshall Islands. J. Atmos. Sci., 53, 2424-2451.
W. D. Collins, J. A. Goldstein, F. P. J. Valero, J. Spinhirne, W. Hart, and P. Pilewskie, 1998: Cloud properties leading to highly reflective tropical cirrus: Interpretations from CEPEX, TOGA COARE, and Kwajalein, Marshall Islands. J. Geophys. Res., 103, 8805-8812.

Houghton, J. T., Y. Ding, D. J. Griggs, M, Noguer, P. J. van der Linden, and D. Xaiosu, Eds. 2001: Climate Change 2001: The Scientific Basis. Cambridge University Press, 944 pp.

Johnson, R. H., T. M. Rickenbach, S. A. Rutledge, P. E. Ciesielski, and W. H. Schubert, 1999: Trimodal characteristics of tropical convection. J. Climate, 12, 2397-2418.

Kalnay, E., and Coauthors, 1996: The NCEP/NCAR 40-year reanalysis project. Bull. Amer. Meteor. Soc., 77, 437-471.

Khain, A. P., D. Rosenfeld, and A. Pokrovsky 2001: Simulating convective clouds with sustained supercooled liquid water down to $-37.5^{\circ} \mathrm{C}$ using a spectral microphysics model. Geophys. Res. Lett., 28, 3887-3890.

Khairoutdinov, M. F., and D. A. Randall, 2001: A cloud resolving model as a cloud parameterization in the NCAR Community Climate System Model: Preliminary results. Geophys. Res. Lett., 28, 3617-3620.

Kummerow, C., W. Barnes, T. Kozu, J. Shiue, and J. Simpson, 1998: The Tropical Rainfall Measuring Mission (TRMM) sensor package. J. Atmos. Oceanic Technol., 15, 809-817.

- and Coauthors, 2001: The evolution of the Goddard profiling algorithm (GPROF) for rainfall estimation from passive microwave sensors. J. Appl. Meteor., 40, 1801-1820.

Lin, B., B. A. Wielicki, L. H. Chambers, Y. Hu, and K.-M. Xu, 2002: The iris hypothesis: A negative or positive cloud feedback? $J$. Climate, 15, 3-7.

Lindzen, R. S., M.-D. Chou, and A. Y. Hou, 2001: Does the earth have an adaptive infrared iris? Bull. Amer. Meteor. Soc., 82, 417-432.

Lucas, C., E. J. Zipser, and B. S. Ferrier, 2000: Sensitivity of tropical West Pacific oceanic squall lines to tropospheric wind and moisture profiles. J. Atmos. Sci., 57, 2351-2373.

Machado, L. A. T., W. B. Rossow, R. L. Guedes, and A. W. Walker, 1998: Life cycle variations of mesoscale convective systems over the Americas. Mon. Wea. Rev., 126, 1630-1654.

Mohr, K. I., and E. J. Zipser, 1996: Mesoscale convective systems defined by their $85-\mathrm{GHz}$ ice scattering signature: Size and intensity comparison over tropical oceans and continents. Mon. Wea. Rev., 124, 2417-2437.

— J. J. Famiglietti, and E. J. Zipser, 1999: The contribution to tropical rainfall with respect to convective system type, size, and intensity estimated from the $85-\mathrm{GHz}$ ice-scattering signature. $J$. Appl. Meteor., 38, 596-606.

Nesbitt, S. W., E. J. Zipser, and D. J. Cecil, 2000: A census of precipitation features in the Tropics using TRMM: Radar, ice scattering, and lightning observations. J. Climate, 13, 4087-4106.

Petersen, W. A., S. A. Rutledge, and R. E. Orville, 1996: Cloud-toground lightning observations from TOGA COARE: Selected results and lightning location algorithms. Mon. Wea. Rev., 124, $602-620$.

Ramanathan, V., and W. Collins, 1991: Thermodynamic regulation of ocean warming by cirrus clouds deduced from observations of the 1987 El Niño. Nature, 351, 27-32.

Rayner, N., D. E. Parker, C. K. Folland, E. B. Horton, L. V. Alexander, and D. P. Rowell, 2002: The global sea-ice and sea surface temperature (HadISST) data sets. [Available online at http://dss. ucar.edu/datasets/ds277.3.]

Rickenbach, T. M., and S. A. Rutledge, 1998: Convection in TOGA COARE: Horizontal scale, morphology and rainfall production. J. Atmos. Sci., 55, 2715-2729.

Rosenfeld, D., and W. L. Woodley, 2000: Deep convective clouds with sustained highly supercooled liquid water until $-37.5^{\circ} \mathrm{C}$. Nature, 405, 440-442.

Smith, E. A., A. Mugnai, H. J. Cooper, G. J. Tripoli, and X. Xiang, 1992: Foundations for statistical-physical precipitation retrieval from passive microwave satellite measurements. Part I: Bright- 
ness-temperature properties of a time-dependent cloud-radiation model. J. Appl. Meteor., 31, 506-531.

Wielicki, B. A., B. R. Barkstrom, E. F. Harrison, R. B. Lee III, G L. Smith, and J. E. Cooper, 1996: Clouds and the Earth's Radiant Energy System (CERES): An Earth Observing System Experiment. Bull. Amer. Meteor. Soc., 77, 853-868.

Wigley, T. M. L., and S. C. B. Raper, 2001: Interpretation of high projections for global-mean warming. Science, 293, 451-454.

Xu, K.-M., and Coauthors, 2002: An intercomparison of cloud-resolving models with the ARM summer 1997 IOP data. Quart. J. Roy. Meteor. Soc., 128, 593-624.

Yao, M.-S., and A. D. Del Genio, 1999: Effects of cloud parame- terization on climate changes in the GISS GCM. J. Climate, 12, 761-779.

Ye, B., 1999: Cumulus anvil cloud properties, large-scale conditions, and climate change. Ph.D. dissertation, Columbia University, $220 \mathrm{pp}$.

A. D. Del Genio, and K. K.-W. Lo, 1998: CAPE variations in the current climate and in a climate change. J. Climate, 11, 19972015.

Zipser, E. J., and K. R. Lutz, 1994: The vertical profile of radar reflectivity of convective cells: A strong indicator of storm intensity and lightning probability? Mon. Wea. Rev., 122, 17511759. 